\title{
Padrões de concentração regional da indústria de transformação brasileira
}

Regional concentration patterns of the Brazilian manufacturing industry

\begin{abstract}
The study analyzes changes in regional concentration patterns of the Brazilian manufacturing industry in recent period (2007. 2014). By means of a density function $F_{\gamma}$ estimated from the agglomeration index of Elisson-Glaeser, it was found that the Brazilian industry faces a process of geographical deconcentration that evolves rapidly, around $2.7 \%$ per year, but with varying intensity among sectors and Brazilian macro-regions. Thus, there is a faster process in the North and Northeast, less in the South and Southeast and stagnant in the Midwest, which accentuated the process of regional disparity. The most striking changes occurred in the North and resulted from the poor performance of the capital goods and durables industry, concentrated in the Manaus Free Trade Zone. In the South, geographical deconcentration occurs slowly and evenly across sectors of the manufacturing industry.
\end{abstract}

\section{Keywords}

geographic concentration, manufacturing industry, agglomeration index.

JEL Codes R11, R12.
André Luiz Ferreira e Silva (1)

Marcelo Bentes Diniz (1)

(1) Universidade Federal do Pará

\section{Resumo}

O presente estudo analisa mudanças nos padrões de concentração regional da indústria de transformação brasileira em período recente (2007-2014). Por meio de uma função densidade $\mathrm{F}_{\gamma}$ estimada a partir do indice de aglomeração Ellison-Glaeser, constatou-se que a indústria brasileira enfrenta um processo de desconcentração geográfica que evolui rapidamente, em torno de $2,7 \%$ ao ano, mas com intensidade variada entre setores e macrorregiões brasileiras. Assim, verifica-se um processo mais acelerado nas regiões Norte e Nordeste, menos nas regiões Sul e Sudeste e estagnado na região Centro-Oeste, o que acentuou o processo de disparidade regional. As mudanças mais impactantes ocorreram no Norte e resultaram do fraco desempenho das indústrias de bens de capital e de bens duráveis, concentradas na Zona Franca de Manaus. No Sul, a desconcentração geográfica ocorre de forma lenta e equilibrada entre setores da indústria de transformação.

\section{Palavras-chave}

concentração geográfica, indústria de transformação e indice de aglomeração.

Códigos JEL R11, R12. 


\section{Introdução}

No início da década de 1980, no esgotamento do processo de industrialização, a matriz industrial brasileira apresentava elevada solidez, com fortes sinais de integralidade intersetorial, representada pela produção e comercialização de bens intermediários, bens de consumo duráveis, da indústria tradicional e de capital. Nesse período, a ideia de desenvolvimento voltado para dentro, que norteou a industrialização, refletia-se no baixo coeficiente de importação, especialmente entre insumos destinados à transformação industrial, cujos projetos começaram a maturar no final da década de 1970 (Cano, 2007).

No entanto, o elevado protecionismo da política econômica acarretou distorções estruturais, promovendo atraso tecnológico e declínio da produtividade para níveis inferiores aos padrões internacionais. A falta de dinamismo ficou mais evidente com a abertura comercial dos anos de 1990, quando a indústria de bens de capital e de bens duráveis começou a perder força e participação no emprego e no Valor da Transformação Industrial (Cano, 2007). Desde então, mudanças estruturais vêm sendo sustentadas pela maior inserção de bens primários e tradicionais, alterando padrões de concentração industrial entre regiões brasileiras.

A consolidação dessas mudanças ocorreu a partir de 2000, quando a economia entra num ciclo de crescimento fortemente impulsionado pelo boom de demanda por commodities, crescente aumento da renda interna derivada da maior inserção no mercado de trabalho, valorização do salário mínimo, políticas de transferência de renda e expansão do crédito pessoal (Negri; Cavalcante, 2014; Souza, 2015). Para alguns autores, fatores de demanda como o consumo e investimento, juntamente com as exportações, contribuíram com o fortalecimento das aglomerações industriais em todo o país (Saboia, 2013; Saboia; Kubrusly; Barros, 2014; Sobrinho; Azzoni, 2016).

Com a crise de 2007-2008, essas variáveis perderam capacidade de impulsionar o crescimento da economia, e a indústria brasileira entrou em um período crítico de desaceleração. As explicações para o declínio são variadas, porém alguns autores atribuem o baixo crescimento a fatores relacionados à baixa produtividade, elevação dos custos de produção relativos domésticos e à má condução da política econômica fiscal, com consequente perda de competitividade internacional (Bonelli; Pessoa; Matos, 2013; Negri; Cavalcante, 2014; Souza, 2015). 
Políticas anticíclicas foram adotadas, visando entre outras coisas: o reforço à liquidez do setor bancário, direcionado mais especificamente à construção civil e à agropecuária; linhas de crédito às exportações; intervenções do Banco Central do Brasil (BCB) no mercado cambial; estímulo ao crédito por parte dos bancos públicos; redução do Imposto sobre Produtos Industrializados (IPI) para automóveis, eletrodomésticos e produtos da construção; aumento do período de concessão do seguro-desemprego; programa de construção de moradia popular ("Minha Casa, Minha Vida"); redução de tarifas de energia elétrica; desoneração da folha de pagamentos em setores selecionados (Sarti; Hiratuka, 2011; Curado; Curado, 2016; Sarti; Hiratuka, 2017). Esse conjunto de medidas atingiu de forma diferenciada os setores produtivos e pode ter influenciado a distribuição espacial das indústrias no país.

O setor industrial foi impactado diretamente pela Política de Desenvolvimento Produtivo (PDP) que se desdobrou, principalmente, em medidas de caráter tributário, regulatório e de financiamento, como desoneração do IPI para bens de capital, siderurgia e o complexo automotivo, ou, ainda, redução do Imposto de Importação (II) sobre bens de capital (Sarti; Hiratuka, 2011; Curado; Curado, 2016). Havia três eixos de ação: a) linhas de ação horizontais (inovação e desenvolvimento tecnológico, inserção externa/exportações, modernização industrial, ambiente institucional); b) setores estratégicos, em que se destacam softwares, semicondutores, bens de capital, fármacos e medicamentos; e c) atividades portadoras de futuro, em que se destacam os esforços para o desenvolvimento de setores como de biotecnologia, nanotecnologia e energias renováveis.

Em face do exposto, existe um processo de deterioração das aglomerações industriais ocorrendo de forma diferenciada entre regiões, porém mais intenso entre os setores mais dinâmicos da economia. Essa hipótese é avaliada quantificando a grandeza das mudanças nos padrões de concentração geográfica da Indústria de Transformação Brasileira (ITB) entre 2007-2014, dando um enfoque regional ao tema. Estudos recentes analisaram essas mudanças em períodos de expansão dos ciclos macroeconômicos (Saboia, 2013; Saboia; Kubrusly; Barros, 2014; Sobrinho; Azzoni, 2016). Mas, aqui, a análise envolve um período crítico para a ITB, considerado de readaptação à internacionalização produtiva das cadeias globais de valor (Sarti; Hiratuka, 2017).

A hipótese mencionada é avaliada comparando duas funções densidade $F_{\gamma}$ estimadas a partir do índice de aglomeração de Ellison e Glaeser (1997), 
entre divisões (2 dígitos) da Classificação Nacional de Atividades Econômicas, versão 2.0 (CNAE 2.0) em 2007 e 2014. Consideram-se dois cortes espaciais diferentes. $\bigcirc$ primeiro agrega microrregiões em todo o território nacional; e o segundo envolve o contexto das grandes regiões brasileiras (Norte, Nordeste, Centro-Oeste, Sul e Sudeste). Para estimar a grandeza das conexões intersetoriais, a análise é completada com os índices de coaglomeração de Ellison, Glaeser e Kerr (2007). Dessa forma, é possível responder onde o processo de deterioração das aglomerações foi mais (menos) intenso e quais os setores mais (menos) afetados.

De acordo com Ellison e Glaeser (1997), existe um pequeno grupo de indústrias mais concentradas que a média, chamadas de fortemente localizadas, dependentes da presença de vantagens naturais ou dos transbordamentos tecnológicos (technological spillovers). Dado que os parâmetros (média e variância) de $F_{\gamma}$ não são conhecidos, recorre-se à inferência não paramétrica bootstrap para estimar esses valores e submetê-los a teste das hipóteses das mudanças nos padrões de concentração regional.

Este artigo está organizado em cinco seções. Além desta introdução, na segunda seção faz-se uma revisão sobre os principais estudos que trataram do problema da desconcentração industrial a partir da década de 1970. A terceira seção expõe a metodologia empregada e a fonte de dados. A quarta seção foi reservada para a análise dos resultados, e a quinta apresenta as conclusões do estudo.

\section{Desconcentração regional da indústria brasileira}

Revisando os estudos de referência, o objetivo desta seção é destacar as principais mudanças ocorridas nos padrões de concentração regional da indústria brasileira a partir da década de 1970.

Cano (2007) examinou o processo, considerando o estado de São Paulo como grande polo dinamizador do crescimento das demais regiões do país. A análise cobre 1970-2005, mas o período é decomposto em três fases. A primeira que vai de 1970-1980, foi chamada de "desconcentração virtuosa", pois a agricultura, a indústria e serviços apresentaram altas taxas de crescimento, gerando efeitos de encadeamentos recíprocos. As estruturas industriais evoluíram em todas as regiões, com os segmentos de bens intermediários, de consumo duráveis e de capital crescendo à frente do 
de bens de consumo não duráveis. A segunda fase (1980-1989) notabilizou-se pela "desconcentração durante a década perdida", quando apenas a agropecuária cresceu e a diversificação industrial paralisou, devido ao fraco desempenho dos setores de bens de capital e de consumo duráveis, fortemente afetados pela "crise da dívida".

Ainda segundo Cano (2007), a estrutura industrial no Brasil começou a regredir justamente num momento em que o capitalismo mundial acelerava sua reestruturação produtiva. A desconcentração industrial prosseguiu, porém em ritmo mais lento, com sinais de paralisação entre 1985-1989. A terceira fase (1990-2005), denominada de "desconcentração no período neoliberal", emergiu quando a indústria de alto valor adicionado regrediu com a crise fiscal, redução dos investimentos públicos e aumento dos juros. $O$ crescimento passou a depender essencialmente das exportações, beneficiando a agroindústria e o setor mineral. A partir daí, a indústria de transformação começou a perder importância no PIB, iniciando um processo que para alguns autores denota desindustrialização (Cano, 2007; Bresser-Pereira, 2007; Oreiro; Feijó, 2010).

Guimarães Neto (1997) examinou a trajetória das desigualdades regionais no Brasil entre 1975 até o início dos anos de 1990. Para o autor, o período (1975-1985) de "integração produtiva" marca o momento em que frações de capitais começaram a se mover da região Sudeste para regiões periféricas como o Nordeste. É o período em que o processo de desconcentração industrial vivenciado pela economia brasileira se apresenta de forma mais clara. $O$ esgotamento desse processo ocorreu em 1985 e tem relação estreita com o agravamento da crise fiscal e financeira do Estado brasileiro. $O$ autor ressalta que o processo ocupou várias dimensões. Houve desconcentração inter-regional, relacionada com a perda de participação da região Sudeste; mas houve também um processo de desconcentração intra-regional, que afetou estados de menor importância econômica das regiões Sul e Sudeste.

Introduzindo o conceito de "campo aglomerativo", Azzoni (1986) focalizou na interiorização da indústria de transformação no estado de São Paulo. $O$ autor argumentou que o surgimento de vantagens locacionais relacionadas às economias de urbanização no interior, combinadas com deseconomias de urbanização na área metropolitana de São Paulo (AMSP), foi determinante para o espraiamento da indústria a partir da década de 1970. Azzoni (1986) negava que estivesse em curso um processo de "re- 
versão da polarização". Para o autor, "a desconcentração é concentrada" porque as cidades médias, que se desenvolveram a partir da década de 1970 e que ofereciam melhores condições para a localização, estavam nas proximidades de grandes polos industriais, especialmente da AMSP.

Diniz (1993) questiona o resultado Azzoni (1986) por entender que a metodologia empregada e a forma de tratamento dos dados não permitem um exame mais rigoroso sobre a extensão geográfica da desconcentração industrial. Para o autor, o espraiamento industrial no Brasil não se deu apenas dentro do limitado raio de $150 \mathrm{~km}$ da AMSP, mas envolveu ampla região poligonal que vai do centro de Minas Gerais ao nordeste do Rio Grande do Sul, corta o oeste dos estados de Santa Catarina, Paraná e São Paulo e vai até o Triângulo Mineiro.

De acordo com Diniz (1993), Diniz e Crocco (1996), o desenvolvimento poligonal foi determinado pela interação das seguintes forças: o surgimento de deseconomias de urbanização na AMSP e de economias de aglomeração em outros centros urbanos; crescente integração do mercado nacional proporcionada pelos gastos com infraestrutura de transporte, energia e telecomunicações; a política econômica de redução das desigualdades regionais e os fortes incentivos fiscais; busca por novas fontes de recursos naturais e estímulos da política de incentivo às exportações; melhores condições de oferta de trabalho e distribuição de renda, especialmente no Sul do país; e a concentração dos gastos em pesquisa no eixo Sul-Sudeste.

Ressalta-se que o período que vai de 1985 a 1996 é marcado por sérias dificuldades de acesso às informações estatísticas sobre o desempenho da indústria de transformação, o que comprometeu a avaliação das mudanças regionais.

Cano (2007) chega a afirmar que a substituição do Censo Industrial pela Pesquisa Industrial Anual (PIA) deixou um vazio censitário entre 1985 a 1996. Não obstante, para Guimarães Neto (1997), as informações disponíveis nesse período não permitem concluir pela continuidade da desconcentração nem pela presença de um processo de reconcentração, embora existam indícios de reestruturação produtiva da economia, como forma de saída da crise.

Diniz e Crocco (1996) argumentam que mudanças tecnológicas e a reestruturação produtiva durante a década de 1990 contribuíram com a regionalização e o dinamismo de novas áreas industriais ao longo do polígono localizado entre as regiões Sul e Sudeste. Mas, para Lemos e Cunha (1996), 
o efeito dispersão da indústria de alta tecnologia observado entre 19861994 limitava-se à AMSP e áreas contíguas.

Outros autores revelaram sensível alteração no processo de desconcentração da indústria regional durante a década de 1990. Nessa direção, usando dados da Relação Anual de Informações Sociais (RAIS), sobre emprego regional dos principais setores da indústria de transformação, Pacheco (1999) concluiu que o processo de desconcentração continua se estendendo para o interior de São Paulo, principais regiões do Sul e Sudeste do Brasil, e até mesmo para o Nordeste, onde a indústria é intensiva em trabalho. Argumenta que a tendência vem acompanhada de forte heterogeneidade dos padrões locacionais, pois a desconcentração não é uniforme entre os setores industriais.

Saboia (2000) identifica importantes transformações nos padrões locacionais nas periferias, especialmente na região Centro-Oeste, com evidências de desconcentração industrial nos estados do eixo Sul-Sudeste, resultado corroborado por Saboia (2013) nos anos 2000.

Resende e Wyllie (2005) foram os primeiros a tratar do problema da localização através de microdados, empregando o índice de aglomeração de Ellison e Glaeser (1997) para avaliar mudanças estruturais da indústria de transformação brasileira no período 1995-2001. Concluíram que não existe um padrão de aglomeração homogêneo entre os setores 4 dígitos da indústria de transformação; e observaram importantes mudanças na ordenação dos níveis de aglomeração, elevando a proporção daqueles setores com baixo grau de aglomeração no ano inicial.

Por seu turno, usando o mesmo método, Lautert e Araújo (2007) constaram retração no nível de concentração médio da indústria de transformação no período de 1996-2001 e relativa estabilidade na distribuição dos setores mais e menos concentrados. Os resultados serviram para destacar que a concentração é maior nos setores de maior densidade tecnológica e menor nos setores tradicionais.

Lemos et al. (2005) discutem a organização espacial da indústria no Brasil, a partir de uma base de dados que permitiu identificar padrões de localização industrial por município no ano 2000. Os autores constataram existência de poucos polos dinâmicos, denominados Aglomerações Industriais Especiais (AIEs), localizados principalmente em áreas metropolitanas do Sul-Sudeste, onde se concentraram $75 \%$ do produto industrial do país e quase a totalidade das firmas inovadoras, exportadoras e intensiva em escala. 
Na mesma linha, Sobrinho e Azzoni (2016) identificaram 17 aglomerações industriais relevantes (AIR) em 2010, sendo que 65\% delas encontravam-se no eixo Sul-Sudeste do país. Há continuidade do processo de desconcentração industrial no período 2000-2010, mas não há indícios de alterações significativas nos padrões locacionais. Polos industriais tradicionais como São Paulo, Rio de Janeiro e Porto Alegre tiveram baixo crescimento das aglomerações; outros polos no interior das regiões Sul e Sudeste tiveram crescimento mais expressivo, o que não ocorreu no Norte e Nordeste.

Recorrendo à técnica de análise de agrupamento de dados espaciais, Saboia, Kubrusly e Barros (2014) investigam alterações no padrão de aglomeração industrial no Brasil durante 2003 e 2011. Foram identificados quatro grupos básicos que evoluíram para cinco em 2011. Esses grupos se distinguem pela distribuição do emprego, dos estabelecimentos e dos salários. Os autores observaram um claro movimento migratório entre as mesorregiões, principalmente em direção àquelas onde as indústrias difusoras e duráveis exercem forte participação.

\section{Procedimentos metodológicos}

\section{1 Índice de aglomeração industrial}

O índice de aglomeração de Ellison e Glaeser (1997) é interpretado como uma medida de excesso de concentração geográfica, pois elimina da concentração bruta uma parcela de concentração industrial, aferida pelo índice de Hirschman-Herfindahl. Essa propriedade é importante para tornar o índice uma medida equiparável entre setores e regiões. Na sua elaboração, os autores assumem que "a firma escolhe sua localização visando maximizar lucro, mas considera também a influência de economias externas que podem derivar dos transbordamentos tecnológicos ou vantagens naturais". Na ausência de economias externas, o problema de localização passaria a depender unicamente da expectativa de lucro e o problema de localização seria um resultado aleatório semelhante ao dartboard approach.

Os autores iniciam a formalização do índice de aglomeração pelo índice de concentração bruta, dado por: 


$$
G_{s}^{*}=\sum_{i=1}^{N}\left(s_{i, s}-x_{i}\right)^{2}
$$

em que, $x$ é a participação da área $i$ no emprego industrial total e $s$ é a parcela de contribuição da área $i$ na composição do emprego da indústria $s$.

O índice (1) é uma medida relativa, pois compara quanto a participação do emprego da indústria $s$ se distância da média esperada da região onde ela está situada, assim quanto maior for essa distância (dispersão), maior será a concentração geográfica. Contudo, Ellison e Glaeser (1997) argumentam que há pelo menos dois motivos que tornam (1) uma medida imprópria para quantificar aglomerações industriais. Primeiro, porque é extremamente sensível a mudanças no tamanho de plantas; segundo, não é eficaz para comparações regionais, pois também é sensível a mudanças no tamanho de áreas. Por esses motivos, os autores passaram a chamá-lo de "índice de aglomeração bruta".

Para corrigir a segunda distorção, propuseram a seguinte normalização:

$$
G_{s}=\frac{\sum_{i=1}^{N}\left(s_{i, s}-x_{i}\right)^{2}}{\left(1-\sum_{i=1}^{N} x_{i}^{2}\right)}
$$

A correção para diferentes tamanhos de plantas é feita pelo índice de Hirschman-Herfindahl. Assim, o índice Ellison-Glaeser é dado por:

$$
\gamma_{s}=\frac{G_{s}-H_{s}}{1-H_{s}}=\frac{\sum_{i=1}^{N}\left(s_{i, s}-x_{i}\right)^{2} /\left(1-\sum_{i=1}^{N} x_{i}^{2}\right)-H_{s}}{\left(1-H_{s}\right)}
$$

em que $H_{s}=\sum_{k=1}^{K} z_{k}^{2}$ é o índice de Hirschman-Herfindahl, calculado pela participação $z_{k}$ de cada planta $k$ no emprego industrial. Na estrutura do modelo, $H$ é chamado de índice de concentração vertical, porque mede a distribuição do emprego ao longo do setor $s$.

Note-se que o índice (3) elimina da concentração geográfica a diferença correspondente às características estruturais. Por exemplo, se $s$ for uma indústria muito competitiva, formada por um grande número de firmas de pequeno porte, a concentração medida por $H_{s}$ terá pouca importância e (3) dependerá basicamente de $G_{s}$. Mas se a competição for muito imperfeita $\left(G_{s}<H_{s}\right)$, então o poder de monopólio aflora com $\gamma<0$. À medida que o monopólio retrai $\left(G_{s}>H_{s}\right)$, economias de aglomeração florescem com $\gamma$ 
$>0$. Em um caso muito particular, a resultante entre a força de dispersão e concentração pode ser nula $\left(G_{s}=H_{s}\right)$, então a localização da firma não dependeria do espaço $(\gamma=0)$ e tudo se resolveria pelo dartboard approach.

Ellison e Glaeser (1997) propuseram, também, uma medida de coaglomeração entre grupos de indústrias, definido em $m$. O objetivo era quantificar a grandeza de conexões intersetoriais, ou seja, dos efeitos para frente e para trás (backward and forward linkages).

O índice de coaglomeração foi definido da seguinte forma:

$$
\gamma_{M}^{c}=\frac{\left[\sum_{i=1}^{N}\left(s_{i, s}-x_{i}\right)^{2} /\left(1-\sum_{i=1}^{N} x_{i}^{2}\right)\right]-H-\sum_{m=1}^{M} \gamma_{s} w_{s}^{2}\left(1-H_{s}\right)}{1-\sum_{m=1}^{M} w_{s}^{2}}
$$

em que $w$ é a participação da indústria $s$ no emprego total setorial, $H=\sum_{m=1}^{M} w_{s}^{2} H_{s}$ é o índice de Hirschman-Herfindahl calculado para o grupo $m$ como uma média ponderada dos índices $H_{s}$ de cada um dos setores do grupo industrial.

Ellison, Glaeser e Kerr (2007) encontraram uma forma de reduzir a composição do grupo $M$ e propuseram uma medida mais simples de coaglomeração, envolvendo apenas pares de indústrias. ${ }^{1}$

$$
\gamma_{(r, s)}^{c}=\frac{\sum_{i=1}^{N}\left(s_{i, r}-x_{i}\right)\left(s_{i, s}-x_{i}\right)}{1-\sum_{i=1}^{N} x_{i}^{2}}
$$

Trata-se de uma correlação da participação do par industrial $(r, s)$ em relação ao tamanho total da microrregião $x_{i}$. O valor esperado (5) é $E\left(\gamma^{c}\right)=0$. Se $E\left(\gamma^{c}\right)>0$, então $(r, s)$ estão localizadas na mesma microrregião, evidenciando um tipo de interação local entre indústrias diferentes. Mas se $E\left(\gamma^{c}\right)<0$, então o par $(r, s)$ estaria interagindo em microrregiões distintas.

Os índices (3) e (5) são calculados para a divisão (2 dígitos) CNAE 2.0 da indústria de transformação em 2007 e 2014. Toma-se a dimensão da microrregião como unidade básica de área, a qual é agregada em duas escalas superiores: a primeira cobre o contexto do território nacional; e a segunda, o das grandes regiões brasileiras (Norte, Nordeste, Sudeste, Sul e Centro-Oeste). ${ }^{2}$

1 No Apêndice A do artigo Ellison, Glaeser e Kerr (2007) está a demonstração de que o índice (5) segue as mesmas propriedades de (4).

2 Inicialmente, pensou-se em adotar a dimensão do município como unidade básica de área, 
O índice (5) completa a análise das interações locais mais representativas no contexto de cada grande região brasileira. Dessa forma, analisam-se apenas as mudanças nas coaglomerações relevantes fixadas no último decil $E\left(\gamma^{c}\right)>0$ no ano inicial.

Notadamente, o cálculo dos índices requer dados de emprego observados no nível da planta industrial. No Brasil, essas informações são fornecidas pela RAIS do Ministério do Trabalho e Emprego (MTE). A RAIS, como o próprio nome indica, é uma relação de informações a qual a firma é obrigada a declarar anualmente sobre as características do trabalhador e do estabelecimento. Há, portanto, dois relatórios: a RAIS Trabalhador, que contém informações sobre salário, idade, sexo, escolaridade, tempo de serviço e outras informações do trabalhador; e RAIS Estabelecimento, utilizada aqui, e que traz informações sobre as características da firma, como o número de emprego, sua CNAE, tamanho e localização.

Os dados da RAIS têm sido empregados em diversos estudos sobre aglomerações produtivas. Sua principal vantagem está na elevada desagregação espaço-setorial dos dados. No entanto, existem limitações que devem ser ressaltadas. Uma delas diz respeito à forma de declaração, considerando que uma empresa, com várias plantas distribuídas territorialmente, tem a opção de reunir todas as informações e declarar um único endereço, geralmente na CNAE da matriz. Outra desvantagem diz respeito ao problema da informalidade, que tende a ser mais frequente nas regiões menos desenvolvidas. Contudo, estudos mostram que a RAIS apresenta elevado grau de uniformidade, que permite comparar a distribuição de atividade econômica ao longo do tempo (Suzigan et al., 2001; Suzigan et al., 2003).

Para não utilizar apenas o volume de emprego por estabelecimento como variável-chave, ocultando algumas diferenças regionais ou tecnológicas, toma-se o Valor da Transformação Industrial (VTI) como uma forma de auxiliar a análise do desempenho setorial. Essa variável é fornecida pela Pesquisa Industrial Anual da Empresa do Instituto Brasileiro de Geografia e Estatística (PIA Empresa-IBGE), podendo ser observada, inclusive, no nível das grandes regiões brasileiras.

mas como muitos polos industriais ocupam áreas superiores como regiões metropolitanas, entendeu-se que a dimensão da microrregião seria mais apropriada. Vale lembrar que uma das preocupações em Ellison e Glaeser (1997) é corrigir o viés para diferentes tamanhos de áreas. 


\subsection{Padrões de concentração regional}

Padrões de concentração regional (PCR) é uma taxonomia que permite aferir a capacidade de mobilidade da firma de diferentes ramos industriais. Ela foi desenvolvida por Ellison e Glaeser (1997), ao tratarem da concentração geográfica da indústria manufatureira norte-americana. Os autores avaliaram o grau de aglomeração industrial segundo setores 2 e 3 dígitos da SIC (Standard Industrial Classification), distribuídos entre as 50 federações norte-americanas em 1987. Concluíram que a concentração geográfica é assimétrica à direita e segue um padrão lognormal, haja vista que uma importante parcela da estrutura industrial é fortemente localizada devido à presença de vantagens naturais ou transbordamentos tecnológicos.

De acordo com os autores, por meio da media $\overline{\bar{\gamma}}$ e da média $\bar{\gamma}$ da função densidade probabilidade $F_{\gamma}$, é possível identificar quatro padrões locacionais:

a) se $0<\gamma_{s}<\overline{\bar{\gamma}}$, então a indústria $s$ exibe fraca localização;

b) se $\overline{\bar{\gamma}} \leq \gamma_{s} \leq \bar{\gamma}$, então a indústria $s$ exibe moderada localização;

c) se $\bar{\gamma}<\gamma_{s}$, a indústria $s$ é fortemente localizada;

d) se $\gamma_{s}<0$, então $s$ é um monopólio.

Essa taxonomia é empregada de forma independente em cada corte, e a análise das mudanças nos padrões locacionais é dirigida por testes estatísticos baseados em duas amostras.

Suponha duas amostras aleatórias independentes de tamanho $n, x=\left(x_{1}\right.$, $\left.x_{2}, \ldots, x_{n}\right)$ e $y=\left(y_{1}, y_{2}, \ldots, y_{n}\right)$ para $x \in X$ e $y \in Y$. Não havendo mudanças nos padrões locacionais, as funções densidade acumuladas $F_{X}$ e $F_{Y}$ não diferem. Então, testa-se a seguinte hipótese:

$$
H_{0}: F_{X}=F_{Y} v s H_{1}: F_{X} \neq F_{Y}
$$

Se $H_{0}$ é verdadeira, então não existe diferença entre os comportamentos probabilísticos das variáveis aleatórias $X$ e $Y$.

Para (6) é necessário dispor de uma estatística de teste. Suponha que $T(x, y)=T$ seja essa estatística. Suponha ainda que $t$ seja uma variável aleatória distribuída sob $H_{0}$. Uma vez calculado $T$ é possível estimar a probabilidade $\operatorname{Prob}(t \geq T)$, chamada nível de significância alcançado. Então, quanto menor for essa probabilidade, mais forte é a evidência contra a veracidade da $H_{0}$, dado um nível de significância estabelecido a priori. 
O problema prático com o teste (6) refere-se às funções $F_{X}$ e $F_{Y}$, cujos parâmetros são desconhecidos. Uma alternativa inferencial é utilizar técnicas não paramétricas de reamostragem com o bootstrap. Esse método foi desenvolvido por Efron no final da década de 1970, mas todo arcabouço teórico pode ser encontrado em Efron e Tibshirani (1993). A vantagem do bootstrap é a capacidade de estimar consistentemente a média e a variância das distribuições $F_{X}$ e $F_{Y}$.

Suponha que $x=\left(x_{1}, x_{2}, \ldots, x_{n}\right)$ seja um vetor com os valores da amostra original. Então, de posse de um gerador de números aleatórios, é possível gerar $b=1, \ldots, B$ amostras com reposição, chamadas reamostras bootstrap. Suponha que $\bar{x}_{b}^{*}$ seja a média da b-ésima reamostra, então a variância da média populacional é

$$
V(\bar{X})=\frac{1}{B-1} \sum_{b=1}^{B}\left(\bar{x}_{b}^{*}-\bar{x}^{*}\right)^{2}=\sigma_{\bar{X}}^{2}
$$

em que, $\bar{x}^{*}=\frac{1}{B} \sum_{b=1}^{B} \bar{x}_{b}^{*}$ é a média das reamostras.

Assim, se $y$ e $x$ forem os respectivos valores $\gamma$ em 2007 e 2014, é possível comparar as variâncias e as médias dessas populações via bootstrap. Nesse caso, a estatística $F$ deve ser usada para verificar se as variâncias são homogêneas; e através da estatística $t$ verifica-se se a diferença de médias gera um resultado probabilisticamente significativo.

Então, em vez de avaliar (6), confrontam-se as hipóteses:

$$
H_{0}: \frac{\sigma_{\bar{X}}^{2}}{\sigma_{\bar{Y}}^{2}}=1 \text { e } \mu_{X}=\mu_{Y} \text { vs. } H_{1}: \frac{\sigma_{\bar{X}}^{2}}{\sigma_{\bar{Y}}^{2}} \neq 1 \text { e } \mu_{X} \neq \mu_{Y}
$$

Assim como antes, rejeitar $H_{0}$ ao nível de significância 5\% implica mudanças nos padrões de localização industrial, que pode ter dois sentidos: pode indicar tendência concentradora com $\mu_{X}>\mu_{Y}$ ou desconcentração geográfica se $\mu_{X}<\mu_{Y}$.

\section{Resultados e discussões}

\subsection{Diagnóstico dos padrões de concentração industrial}

Os testes baseados em duas amostras apresentados na Tabela 3 visam tes- 
tar a hipótese de mudanças nos padrões de concentração geográfica industrial em dois contextos diferentes: o primeiro compreende o território nacional (Cobertura Brasil); e o segundo, o das grandes regiões brasileiras (Norte, Nordeste, Sudeste, Sul e Centro-Oeste). Eles comparam os parâmetros (média e desvio padrão) de duas populações independentes (cortes 2007 e 2014), cujos valores foram obtidos por meio $B$ de simulação bootstrap de acordo com a Tabela 1.

Tabela 1 Média e desvio padrão do índice de aglomeração $\gamma$ estimada via bootstrap

\begin{tabular}{|c|c|c|c|c|c|c|c|}
\hline \multirow{2}{*}{$\begin{array}{l}\text { Parâ- } \\
\text { metro }\end{array}$} & \multirow[t]{2}{*}{ Cobertura } & \multicolumn{3}{|r|}{2007} & \multicolumn{3}{|r|}{2014} \\
\hline & & $\begin{array}{r}B= \\
500\end{array}$ & $\begin{array}{r}B= \\
1.000\end{array}$ & $\begin{array}{r}B= \\
10.000\end{array}$ & $\begin{array}{r}B= \\
500\end{array}$ & $\begin{array}{r}B= \\
1.000\end{array}$ & $\begin{array}{r}B= \\
10.000\end{array}$ \\
\hline \multirow{6}{*}{ Média } & Brasil & 0,0223 & 0,0221 & 0,0221 & 0,0186 & 0,0182 & 0,0184 \\
\hline & Norte & 0,1088 & 0,1080 & 0,1077 & 0,0762 & 0,0752 & 0,0772 \\
\hline & Nordeste & 0,0362 & 0,0366 & 0,0367 & 0,0298 & 0,0291 & 0,0292 \\
\hline & Sudeste & 0,0262 & 0,0265 & 0,0263 & 0,0212 & 0,0213 & 0,0215 \\
\hline & Sul & 0,0623 & 0,0614 & 0,0620 & 0,0527 & 0,0534 & 0,0535 \\
\hline & Centro-Oeste & 0,0521 & 0,0507 & 0,0508 & 0,0487 & 0,0495 & 0,0498 \\
\hline \multirow{6}{*}{$\begin{array}{l}\text { Desvio } \\
\text { padrão }\end{array}$} & Brasil & 0,0061 & 0,0061 & 0,0060 & 0,0066 & 0,0065 & 0,0064 \\
\hline & Norte & 0,0176 & 0,0182 & 0,0177 & 0,0312 & 0,0326 & 0,0315 \\
\hline & Nordeste & 0,0082 & 0,0083 & 0,0080 & 0,0121 & 0,0126 & 0,0124 \\
\hline & Sudeste & 0,0082 & 0,0085 & 0,0085 & 0,0093 & 0,0091 & 0,0090 \\
\hline & Sul & 0,0322 & 0,0335 & 0,0334 & 0,0268 & 0,0275 & 0,0273 \\
\hline & Centro-Oeste & 0,0147 & 0,0146 & 0,0145 & 0,0187 & 0,0185 & 0,0183 \\
\hline
\end{tabular}

Fonte: Resultado da pesquisa, elaboração própria.

Os resultados indicam não existir diferença sistemática entre os parâmetros da distribuição $\gamma$ quando se aumenta o número de simulações bootstrap no mesmo período de tempo e em qualquer cobertura espacial analisada, demonstrando que a média e a variância (desvio padrão) da função densidade $\gamma$ são estáveis a partir de 500 permutações. No entanto, quando se comparam as mudanças entre 2007 e 2014, têm-se os primeiros sinais de que a média do índice $\gamma$ reduziu no Brasil e nas cinco regiões pesquisadas (Tabelas 1).

A Tabela 2 apresenta os resultados do teste $\mathrm{F}$ e $\mathrm{t}$ para duas amostras considerando 500 simulações bootstrap. $O$ teste $\mathrm{F}$ avalia se as variâncias das duas populações são homogêneas, isto é, testa-se a hipótese nula de que a 
razão de variância é igual a 1, conforme (8). E o teste t avalia se não houve perda de massa nas aglomerações.

O Centro-Oeste é a única região onde a hipótese nula dos testes F e $t$ não pode ser rejeitada conjuntamente a $5 \%$ de probabilidade de erro. As estatísticas t com sinal negativo e significante a $5 \%$ demonstram que as aglomerações retraíram no Norte, Nordeste, Sudeste e Sul. Vale dizer que esse resultado é suficiente para o diagnóstico, pois basta uma mudança em único parâmetro (na média no caso) para que a hipótese de desconcentração geográfica não seja refutada. Tome o caso do Nordeste, ainda que variâncias sejam estatisticamente homogêneas percebe-se que a média da função densidade $F_{\gamma}$ retraiu entre 2007 e 2014.

Tabela 2 Diagnóstico das mudanças nos padrões de concentração industrial

\begin{tabular}{lrrrrr}
\hline \multirow{2}{*}{ Cobertura } & \multicolumn{2}{|c|}{ Teste F para duas variâncias } & \multicolumn{2}{r}{ Teste t para duas médias } \\
\cline { 2 - 5 } & Estatística & Prob. & Estatística & Prob. \\
\hline Brasil & 0,744 & 0,0001 & -12.441 & 0,0000 \\
\hline Norte & 1.452 & 0,0000 & -14.434 & 0,0000 \\
\hline Nordeste & 1.058 & 0,5293 & -13.535 & 0,0000 \\
\hline Sudeste & 1.375 & 0,0000 & -17.995 & 0,0000 \\
\hline Sul & 0,797 & 0,0003 & -11.923 & 0,0000 \\
\hline Centro-Oeste & 0,972 & 0,6539 & $-0,6391$ & 0,5231 \\
\hline
\end{tabular}

Fonte: Resultado da pesquisa, elaboração própria.

\subsection{Padrões de concentração da indústria de transformação brasi- leira}

A partir da metodologia proposta, foi possível identificar as indústrias (2 dígitos, CNAE 2.0) geograficamente mais (menos) concentradas no contexto do território nacional. A Tabela 4 monstra os valores de $\gamma_{s}$, e seus componentes $G_{s}$ e $H_{s}$ a participação no emprego $E(\%)$ e no Valor da Transformação Industrial VTI (\%), bem como a taxa geométrica de variação $\Delta \gamma$, calculada para o período 2007 e 2014. A Figura 1, por sua vez, compara a função densidade das aglomerações no mesmo período.

Nela, a função densidade $F_{\gamma}$ é semelhante à distribuição lognormal, em que a variável de interesse é assimétrica à direita e seu logaritmo é normalmente distribuído, permitindo o uso de testes t e F. Ademais, esse resulta- 
do corrobora os pressupostos do modelo de dartboard approach de Ellison e Glaeser (1997).

$\mathrm{Na}$ Tabela 3, todos os índices $\gamma_{s}$ são estritamente positivos, indicando que as forças de dispersão geográfica foram superiores às que estimularam a concentração vertical das atividades. Significa dizer que todos os setores da ITB oferecem alguma capacidade de produzir economias de aglomeração. Não se trata de um resultado surpreendente, pois foi diagnosticado por autores que investigaram o tema (Resende; Wyllie, 2005; Lautert; Araújo, 2007).

Figura 1 Função densidade $F_{\gamma}$ da indústria de transformação brasileira

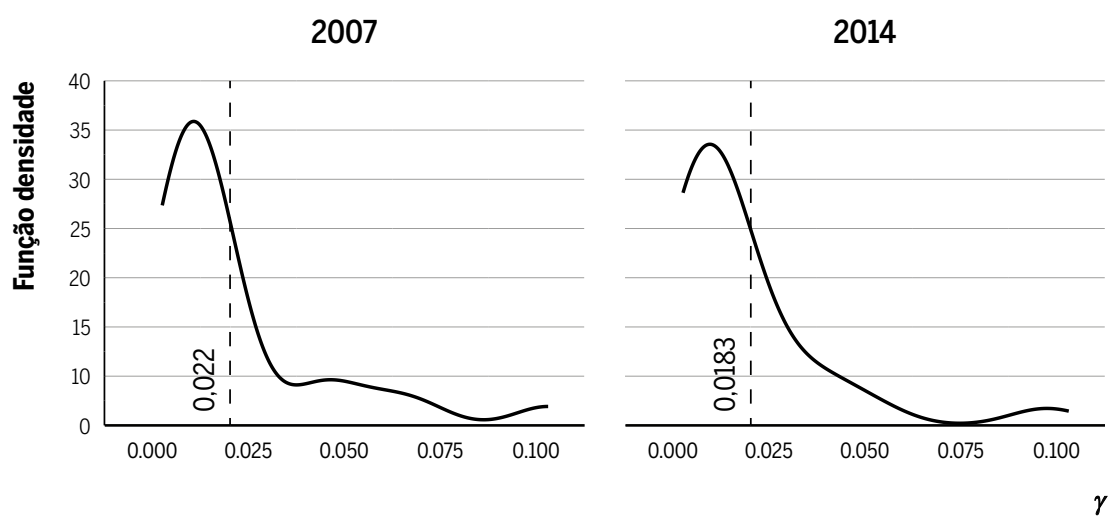

Nota: Linha tracejada é a média.

Fonte: Resultado da pesquisa, elaboração própria.

Analisam-se, agora, as características estruturais dos padrões de concentração. Percebe-se que os setores menos concentrados, com fraca localização (FL), são os mais representativos e responderam por $65,2 \%$ do emprego e $55,6 \%$ do VTI em 2007. Esse padrão é basicamente composto por firmas que pertencem à indústria tradicional (Alimentos, Bebidas, Vestuário e acessórios e Produtos de borracha e de plástico), mas existem também produtores de commodities com reduzido poder de concentração (Papel e celulose, Metalurgia, Minerais não metálicos e Produtos químicos).

As três indústrias menos concentradas produzem commodities (Papel e celulose, Metalurgia e Minerais não metálicos) e sua localização parece determinada por recursos naturais abundantes em todo país. Em geral, a dinâmica do setor de commodities é dirigida por uma grande firma especializada, que 
gera demanda para outras firmas subsidiárias de menor porte. Ferraz, Kupfer e Haguenauer (1996) consideram que sua tecnologia caracteriza-se pela elaboração de produtos homogêneos em grandes volumes. E, segundo a tipificação de Negri et al. (2005), as líderes são firmas especializadas em produtos padronizados, cuja estratégia competitiva atua via mecanismo redutor de custo, em vez de agregar valor ao produto.

A indústria tradicional é composta por firmas pequenas, em sua maioria. São dotadas de um padrão tecnológico homogêneo, intensivo em trabalho e com baixa capacidade de diversificação. Essas características fazem com que seu desenvolvimento tecnológico seja muito dependente de insumos, máquinas e equipamentos fornecidos por outros setores. Ferraz, Kupfer e Haguenauer (1996) argumentam que essas indústrias se caracterizam por elaborarem produtos de menor conteúdo tecnológico e destinados ao consumo final, principalmente. Para Negri et al. (2005), algumas firmas até inovam, porém são menos eficientes nos mais variados sentidos.

Dos 12 setores identificados com fraca localização em 2007 na Tabela 4, 11 estão desconcentrando suas atividades ou as taxas de aglomeração seguem estagnadas. Nesse padrão, apenas Papel e celulose exibe visíveis sinais de concentração geográfica ( $3,1 \%$ a.a.).

No outro extremo da curva (à direita da média na Figura 1), existem cinco indústrias fortemente localizadas (XL), cujo poder de concentração relaciona-se com a presença de vantagens naturais ou com alto conteúdo tecnológico da produção, corroborando o modelo de Ellison e Glaeser (1997). Em geral, são indústrias que operam em mercados imperfeitos e seu poder de precificação permite capturar uma parcela significativa do excedente de renda.

Neste padrão, o Fumo é a indústria mais concentrada e assemelha-se a um típico caso de economias de localização. Por outro lado, os produtores de Farmoquímicos e farmacêuticos, Informática e produtos eletrônicos e de Transporte, exceto veículos indicam que a concentração é reforçada por vantagens competitivas baseadas em atividades inovadoras de produtos e/ou processos.

No estudo de Silva e Suzigan (2014), Farmoquímicos e farmacêuticos aparecem com elevado grau de esforço inovador, bem superior à média nacional. Não obstante, o setor de Equipamentos de transporte, exceto veículos (30), mais especificamente, os Fabricantes de aeronaves (304) formam um grupo de alta intensidade tecnológica. Ao passo que Informática e produtos eletrônicos - as- 
sim como Veículos automotores com moderada localização (ML) - apresenta uma proporção da receita reinvestida em atividade inovadora que supera a média nacional. Pode-se dizer, ademais, que a indústria de Couro é uma extensão da cadeia agropecuária apontada por Silva e Suzigan (2014) como uma estrutura que emprega mediano grau de esforço inovador.

O declínio acelerado das taxas de aglomeração das indústrias com forte localização (Tabela 4) não representa, necessariamente, mobilidade regional. O cenário mais provável é a deterioração macrossetorial dos elos mais dinâmicos (Veículos automotores, Farmoquímicos e farmacêuticos, Informática e produtos eletrônicos e Transporte, exceto veículos). É difícil pensar em mobilidade regional se o poder de concentração desses setores vincula-se a altos custos fixos, depende do intercâmbio tecnológico e de uma ampla rede de fornecedores somente encontrada nos grandes mercados. Além disso, vários estudos mostram que a indústria de transformação enfrenta um processo de atrofia, mais severo entre bens duráveis e de capital (Negri; Cavalcante, 2014; Souza, 2015). Deve-se considerar também que a ITB vem perdendo participação no VTI, que reduziu de $17,6 \%$ para $15,2 \%$ entre 2007 e 2014.

Na faixa intermediária de $F_{\gamma}$, há 7 setores com moderada localização. Suas taxas de aglomeração relativamente dispersas comprometem a identificação de uma tendência para esse padrão (Tabela 4), em consequência, não há como estabelecer um padrão tecnológico característico. No entanto, dois casos merecem destaque. $O$ primeiro refere-se à concentração de Coque e derivados de petróleo, que segue o ritmo intenso (3,4\% a.a.) a ponto de alterar o padrão de localização (ML/XL). O segundo refere-se a Materiais elétricos que segue numa tendência desconcentradora, intensa o suficiente, a ponto de alterar o padrão para fraca localização (ML/FL).

As evidências mostram que o processo de desconcentração regional foi determinado pela dispersão de setores tradicionais e de produtores de commodities. Esse processo também é reforçado pela deterioração nos setores mais dinâmicos da ITB. Tomando a média da Figura 1 como referência, estima-se que as aglomerações retraíram à taxa de 2,7\% ao ano.

\subsection{Padrões de concentração nas regiões periféricas}

Os padrões de concentração periféricos têm particularidades que merecem 
destaque. Em geral, a aglomeração está ancorada no desempenho de uma ou poucas firmas de grande porte, remetendo ao aparecimento de monopólio ou de estruturas oligopolizadas com forte poder de concentração. Salvo exceções, as estruturas dependem da produção de firmas especializadas em bens primários ou semielaborados tipo commodities. A indústria com fraca localização, por outro lado, atua na produção de bens com baixo valor adicionado, atendendo diretamente ao mercado de consumo local. As externalidades geradas são essencialmente pecuniárias, manifestam-se no preço dos insumos e/ou no custo unitário do salário. Cadeias incompletas ou fortemente especializadas restringem o alcance das conexões intersetoriais e do processo de diversificação produtiva. Devido à reduzida escala da indústria de bens de capital e de bens duráveis, os transbordamentos tecnológicos têm baixo alcance nas periferias.

Estruturas com essas características são típicas das regiões Norte, Nordeste e Centro-Oeste. As Tabelas 6, 8 e 10, no final de cada subseção, demonstram os índices de concentração Ellison-Glaeser, a participação no emprego E\% e no Valor da Transformação Industrial VTI\%. As Figuras 2, 3 e 4 exibem as densidades das aglomerações regionais, e as Tabelas 5, 7 e 9 exibem os índices de coaglomeração de Ellison-Glaeser-Kerr (EGK).

\subsubsection{Norte}

A Tabela 4 mostra a presença de seis indústrias com poder de monopólio em 2007, sendo que quatro mantiveram o padrão no final de 2014. O poder de monopólio de Manutenção de máquinas e equipamentos é insignificante, pois rapidamente foi corrigido pela dispersão geográfica. Os produtores de Coque e derivados do petróleo, por outro lado, têm forte poder de concentração, mas dispersaram a produção por diferentes microrregiões, alterando seu padrão de monopólio para forte localização (MP/XL). Contudo, chama atenção o poder de concentração vertical presente na estrutura no Norte, dado que os monopólios cresceram tanto na formação de emprego (de 5,4\% para 6,5\%) quanto no VTI regional (de 5,2\% para 5,7\%). A razão disso estaria no alto custo unitário da produção, que reduz quando é concentrada em uma ou poucas plantas industriais. 


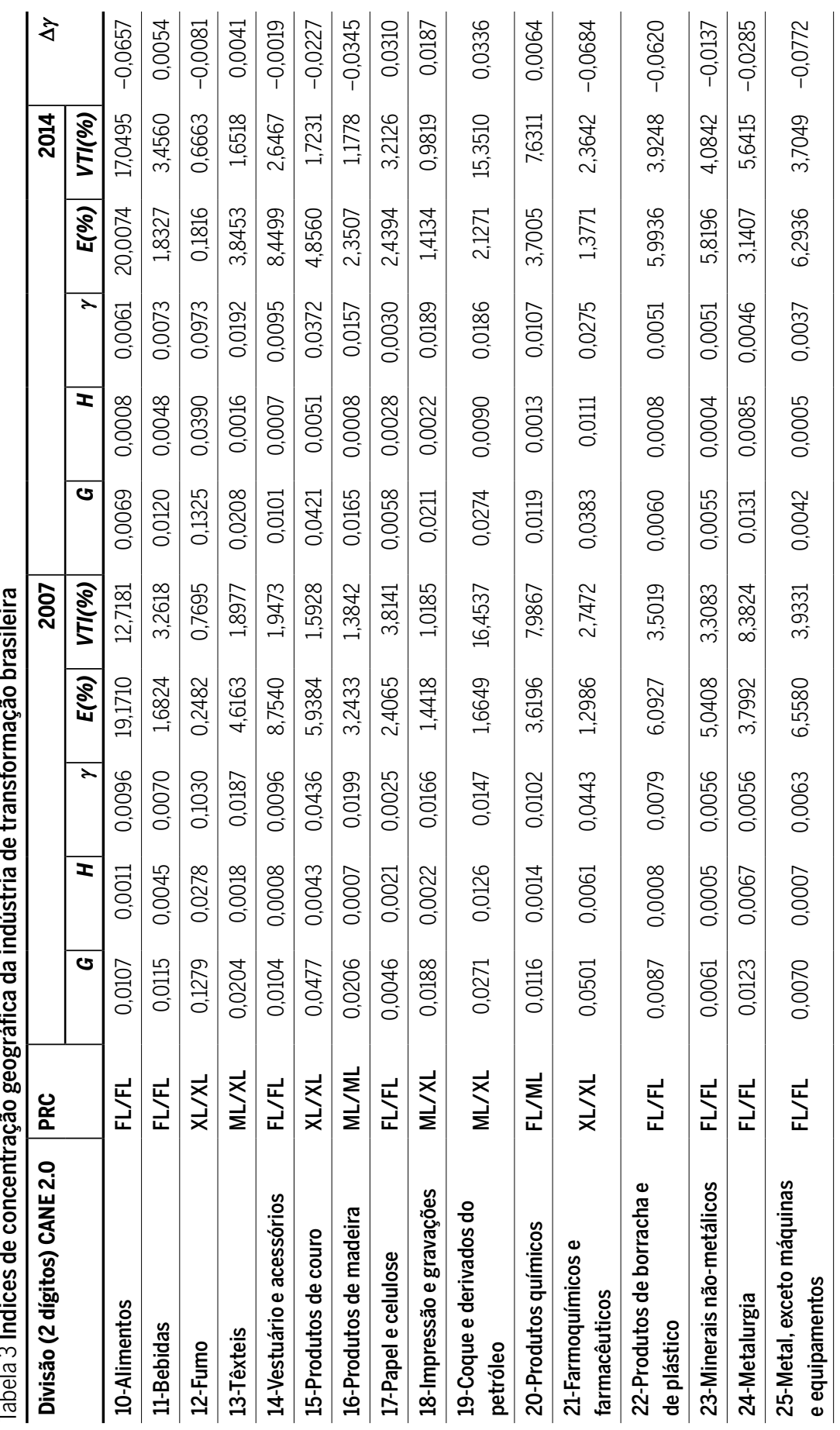




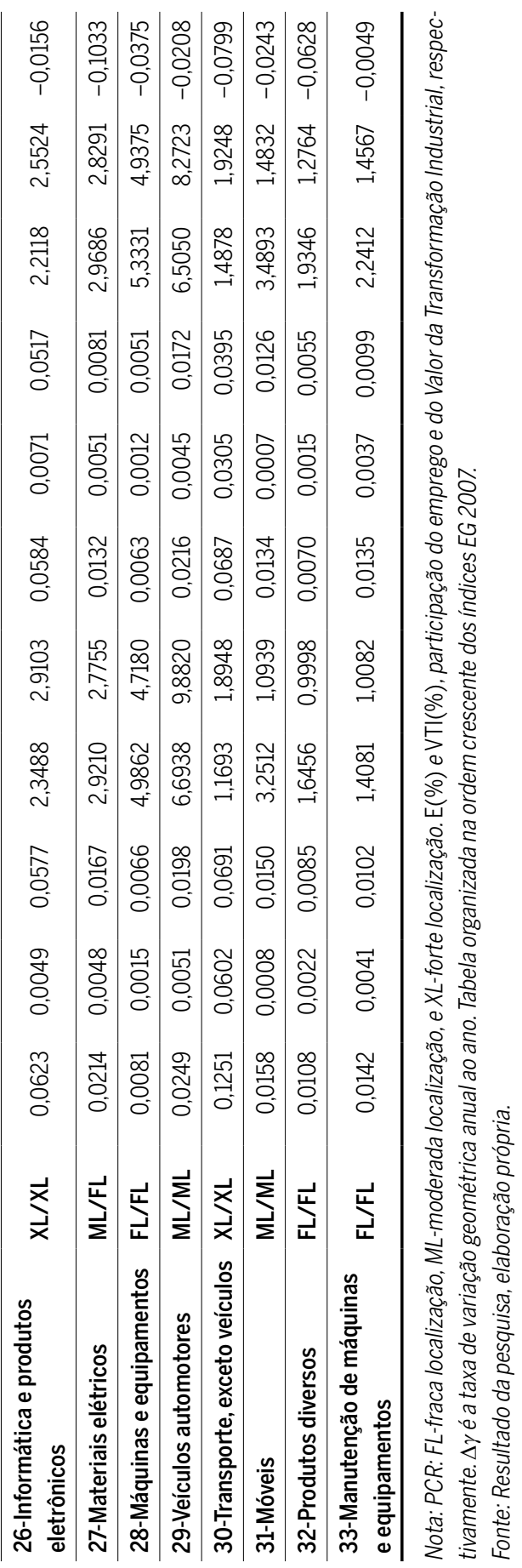




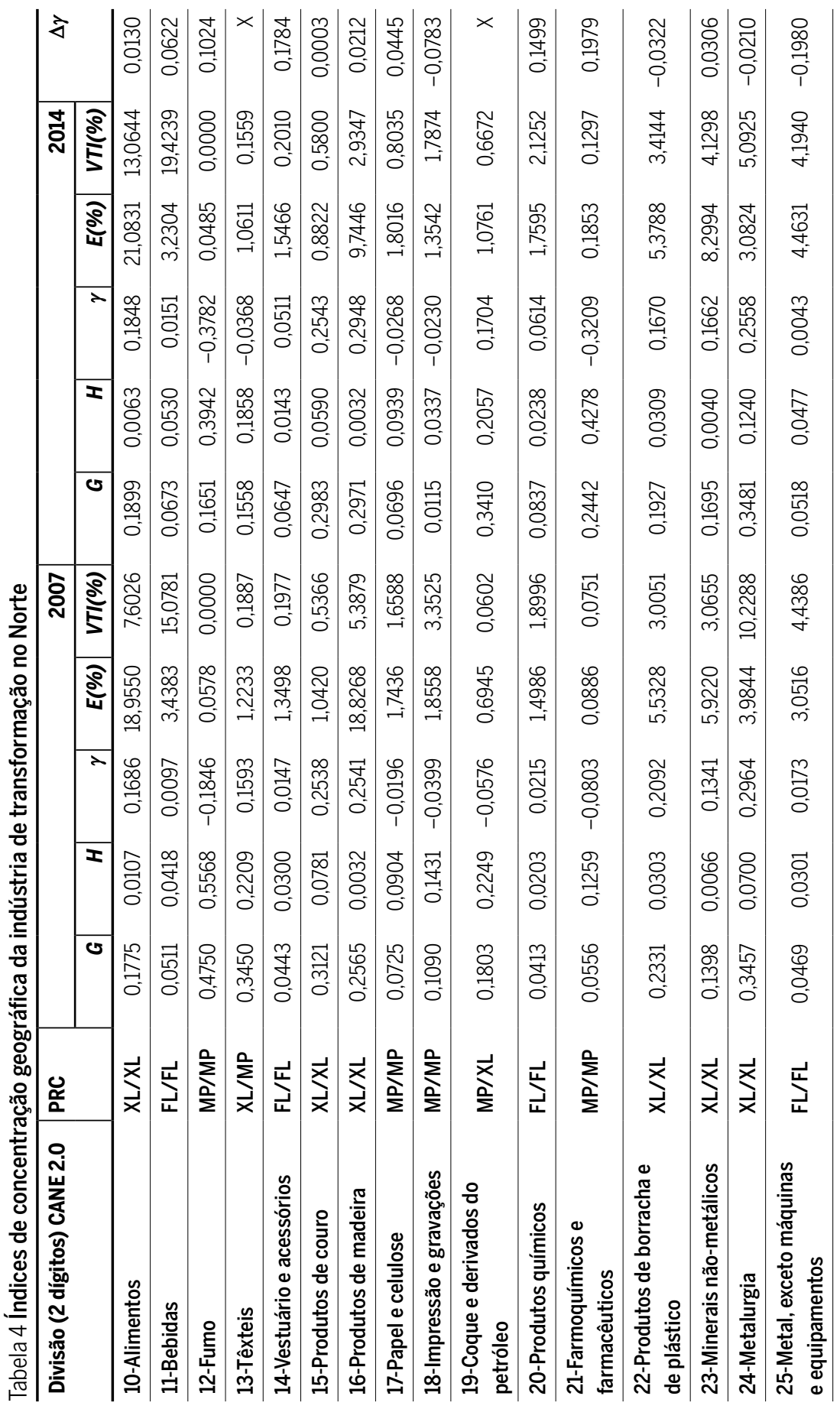




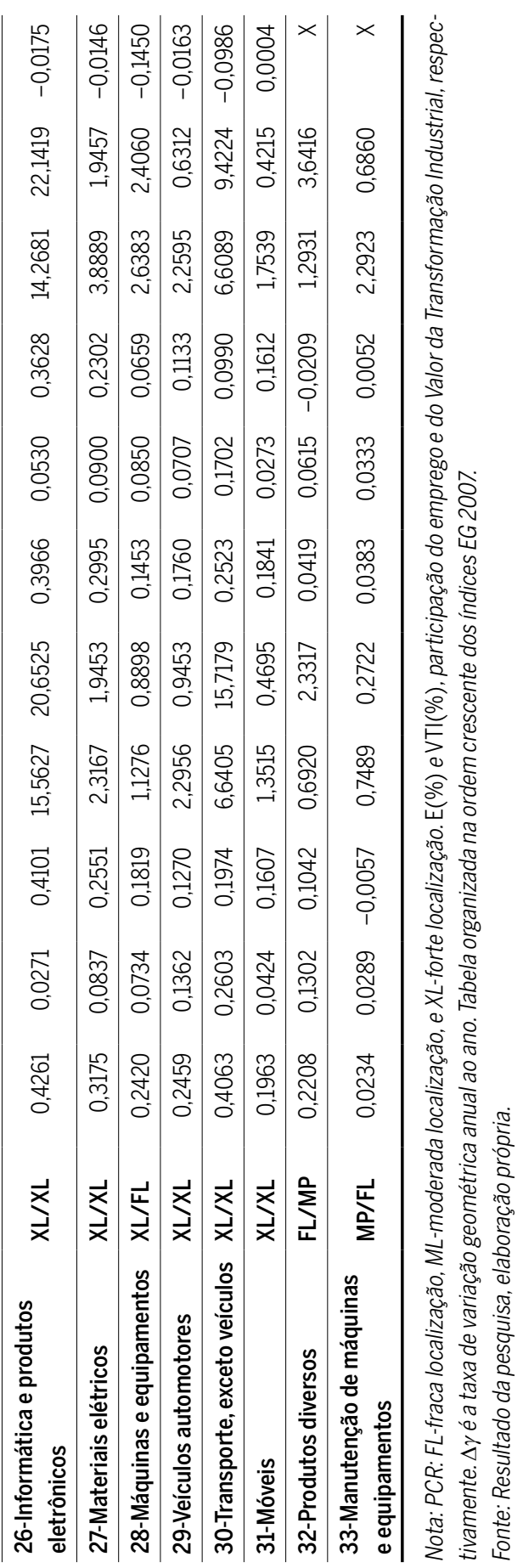


Figura 2 Função densidade $F_{\gamma}$ da indústria de transformação na região Norte
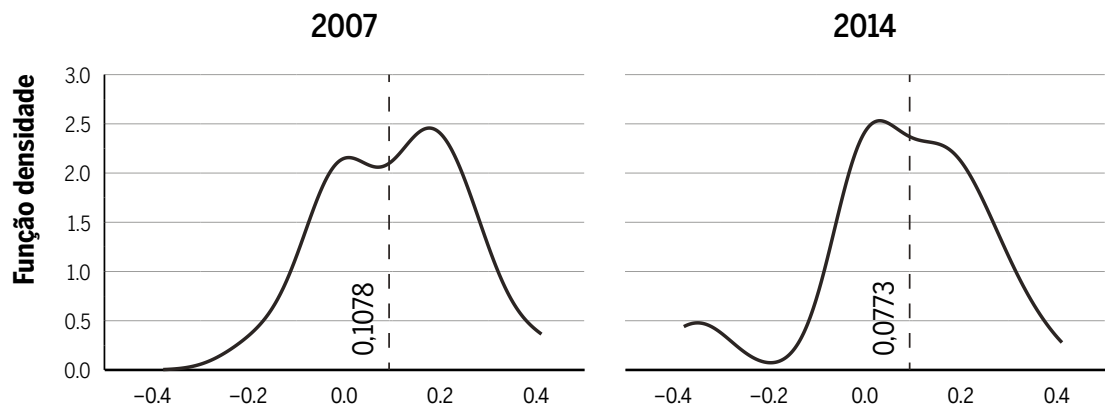

Nota: Linha tracejada é a média.

Fonte: Resultado da pesquisa, elaboração própria.

A função densidade apresenta duas modas, indicando que estruturas diferentes ocupam espaços econômicos diferentes (Figura 2). A primeira moda é menos relevante, porque suas indústrias têm baixa capacidade de formação de emprego e VTI (Tabela 4). Destaque para a forte participação no VTI do setor de Bebidas, que vem expandindo suas atividades em toda a região.

A segunda moda é composta por indústrias heterogêneas e fortemente localizadas, subdivididas em três categorias:

a) existem atividades concentradas em torno da produção de commodities minerais (Minerais não metálicos e Metalurgia);

b) outras dependem da extração florestal (Produtos de madeira) ou são extensões da cadeia agropecuária (Alimentos);

c) porém, há um grupo composto por seis setores dinâmicos (Informática e eletrônicos, Transporte, exceto veículos, Materiais elétricos, Produtos de borracha e plástico, Máquinas e equipamentos e Veículos automotores), nos quais o desempenho depende da complementaridade intersetorial.

O último grupo está concentrado na Zona Franca de Manaus (ZFM), polo mais dinâmico da região Norte. A complementaridade é evidenciada na Tabela 5, que mostra 14 coaglomerações relevantes, fixadas no último decil da distribuição do índice de EGK em 2007. O principal resultado refere-se ao declínio absoluto desse indicador, indicando que a desconcentração no Norte está mais ligada à deterioração dos setores mais dinâmicos da ZFM. Estima-se que todas as aglomerações regionais retrocederam a taxa média de $4,7 \%$ a.a., portanto, superior à média nacional ( $-2,7 \%$ a.a.). 
Tabela 5 Principais índices de coaglomeração industrial no Norte

\begin{tabular}{l|llr|r|r}
\hline $\mathbf{( r ; s )}$ & Setor $\boldsymbol{r}$ & Setor $\boldsymbol{s}$ & $\mathbf{2 0 0 7}$ & $\mathbf{2 0 1 4}$ & $\mathbf{\Delta \gamma \mathbf { c }}$ \\
\hline $\mathbf{( 2 6 ; 3 0 )}$ & Informática e eletrônicos & Transporte, exceto veículos & 0,4298 & 0,3242 & $-0,0403$ \\
\hline $\mathbf{( 2 6 ; 2 7 )}$ & Informática e eletrônicos & Materiais elétricos & 0,3799 & 0,3555 & $-0,0095$ \\
\hline $\mathbf{( 2 7 ; 3 0 )}$ & Materiais elétricos & Transporte, exceto veículos & 0,3705 & 0,2842 & $-0,0379$ \\
\hline $\mathbf{( 2 6 ; 2 9 )}$ & Informática e eletrônicos & Veículos automotores & 0,3308 & 0,2685 & $-0,0298$ \\
\hline $\mathbf{( 2 6 ; 2 8 )}$ & Informática e eletrônicos & Máquinas e equipamentos & 0,3299 & 0,2356 & $-0,0481$ \\
\hline $\mathbf{( 2 9 ; 3 0 )}$ & Veículos automotores & Transporte, exceto veículos & 0,3220 & 0,2116 & $-0,0600$ \\
\hline $\mathbf{( 2 8 ; 3 0 )}$ & Máquinas e equipamentos & Transporte, exceto veículos & 0,3213 & 0,1852 & $-0,0787$ \\
\hline $\mathbf{( 2 2 ; 2 6 )}$ & Produtos de borracha e plástico & Materiais elétricos & 0,3206 & 0,2804 & $-0,0191$ \\
\hline $\mathbf{( 2 6 ; 3 2 )}$ & Informática e eletrônicos & Produtos diversos & 0,3181 & 0,1149 & $-0,1455$ \\
\hline $\mathbf{( 2 2 ; 3 0 )}$ & Produtos de borracha e plástico & Transporte, exceto veículos & 0,3123 & 0,2231 & $-0,0480$ \\
\hline $\mathbf{( 3 0 ; 3 2 )}$ & Transporte, exceto veículos & Produtos diversos & 0,3099 & 0,0899 & $-0,1767$ \\
\hline $\mathbf{( 2 7 ; 2 9 )}$ & Materiais elétricos & Veículos automotores & 0,2842 & 0,2319 & $-0,0291$ \\
\hline $\mathbf{( 2 7 ; 2 8 )}$ & Materiais elétricos & Máquinas e equipamentos & 0,2842 & 0,2034 & $-0,0478$ \\
\hline $\mathbf{( 2 2 ; 2 7 )}$ & Produtos de borracha e plástico & Materiais elétricos & 0,2767 & 0,2448 & $-0,0175$ \\
\hline
\end{tabular}

Nota: Tabela organizada em ordem decrescente dos índices EGK2007. 4 c é a taxa de variação geométrica. Fonte: Resultado da pesquisa, elaboração própria.

\subsubsection{Nordeste}

A Tabela 6 mostra que o poder de monopólio tem crescido no Nordeste aumentando sua participação no emprego (de 3,4\% para $6,6 \%$ ) e no VTI (de 5,9\% para 12,0\%). Bebidas e Metalurgia têm se destacado pela capacidade de concentrar a produção em única planta. Transporte, exceto veículos migrou de monopólio para forte localização, indicando redistribuição espacial de suas atividades produtivas. Farmoquímicos e farmacêuticos é uma indústria de baixa representatividade regional, a qual passou a concentrar verticalmente sua produção.

A taxa de variação do índice EG na Tabela 6 mostra que apenas três setores (Produtos diversos, Produtos de couro e Máquinas e equipamentos) estão concentrando suas atividades. Assim, os monopólios e a dispersão geográfica dos demais setores determinaram a retração média das taxas de aglomeração, implicando uma $F_{\gamma}$ mais assimétrica à esquerda (Figura 3). 


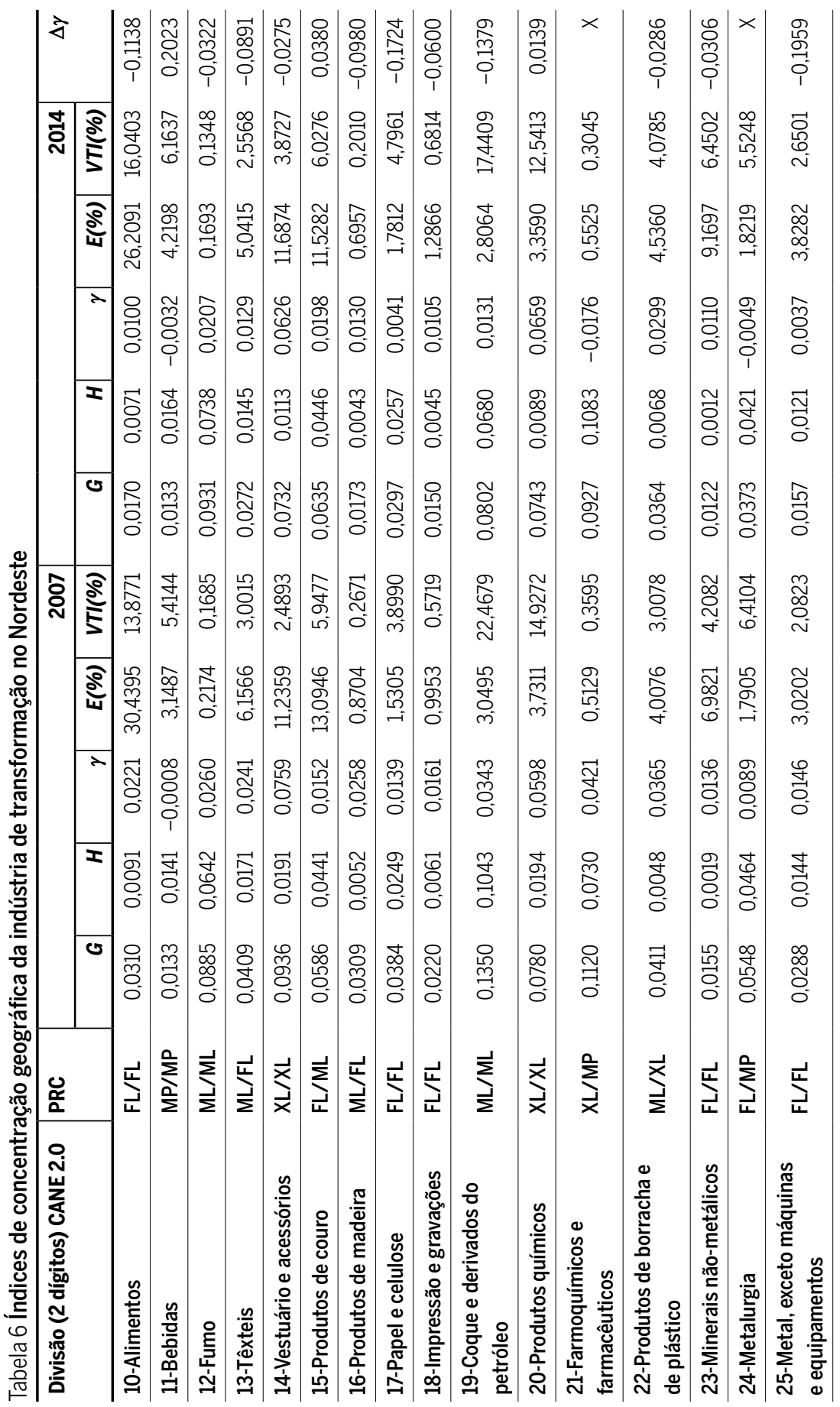




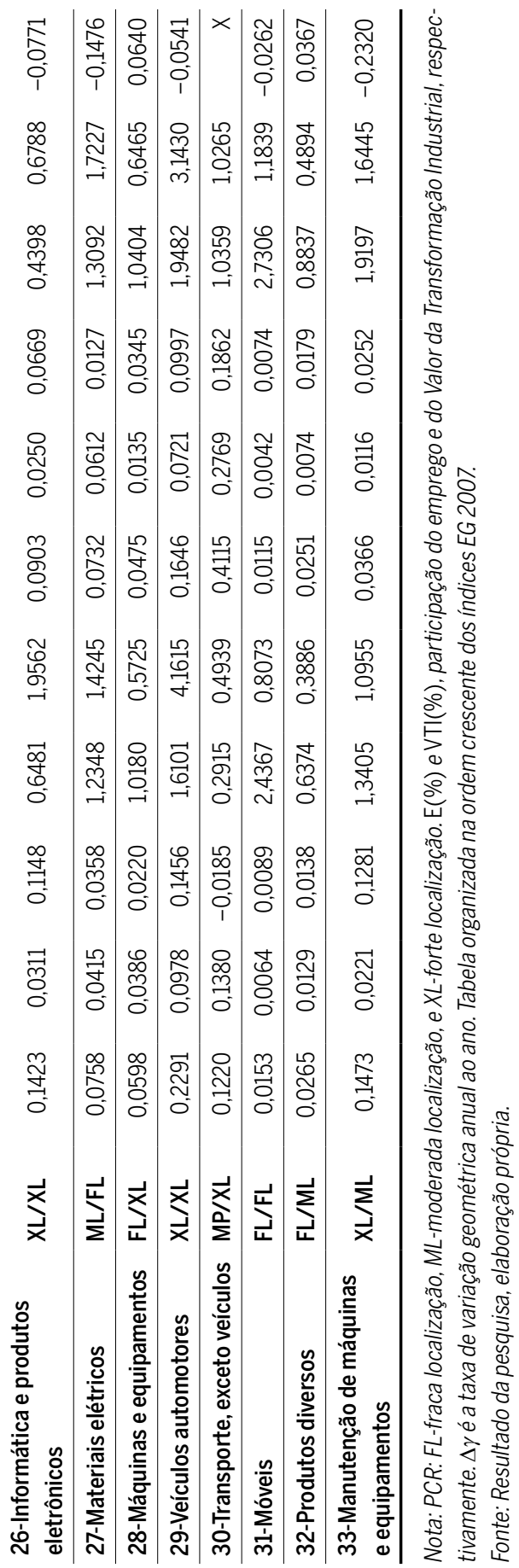


No Nordeste a indústria de transformação tem traços característicos que relacionam a forte presença da indústria tradicional ao seu padrão de localização. Esse grupo é composto por sete setores (Alimentos, Têxteis, Vestuário e acessórios, Produtos de couro, Produtos de madeira, Impressão e gravações e Móveis), que absorveram $60 \%$ do emprego regional, no entanto sua contribuição no VTI não chega a 30\%. Dadas as características (a mais marcante é o uso intensivo de mão de obra), grande parte dos setores é de fraca ou moderada localização. Vestuário e acessórios é exceção, pois a produção está fortemente concentrada na área metropolitana de Fortaleza, estado do Ceará.

Há outro conjunto de indústrias fortemente concentradas no polo de Camaçari-Bahia, onde as características estruturais se aproximam de atividades exercidas por firmas que inovam e diferenciam produto. Entre as coaglomerações relevantes, as indústrias de Veículos automotores, Informática e eletrônicos, Materiais elétricos, Produtos de borracha e plástico e Produtos quimicos determinam a concentração de firmas em Camaçari (Tabela 7).

A Tabela 7 mostra também dois tipos de coaglomerações formando-se em outros polos. A primeira é composta por firmas que operam na indústria metalmecânica, com destaque para Metalurgia, Máquinas e equipamentos e Manutenção de máquinas e equipamentos; e a segunda, por firmas tradicionais, em que o processo é dirigido por Vestuário e acessórios.

Figura 3 Função densidade $F_{\gamma}$ da indústria de transformação na região Nordeste
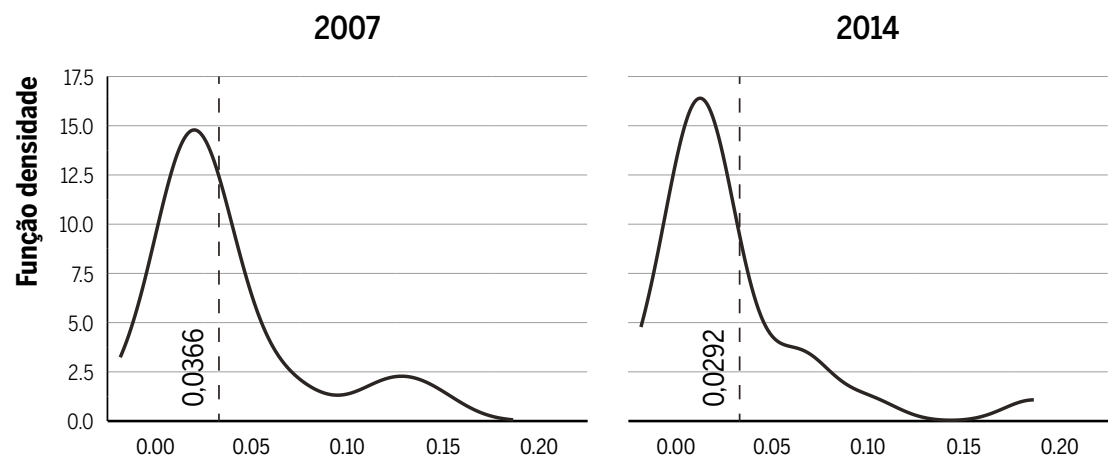

Nota: Linha tracejada é a média.

Fonte: Resultado da pesquisa, elaboração própria. 
Lemos et al. (2005) identificaram quatro Aglomerações Industriais Espaciais (AIEs) no Nordeste em 2000. Segundo os autores, Salvador (polo de Camaçari) é a mais relevante, tanto em termos de escala (tamanho do VTI) como de seu transbordamento espacial. A segunda AIE mais importante localizava-se em Fortaleza, onde firmas especializadas em produtos padronizados responderam por $86 \%$ do VTI gerado pelo conjunto de firmas da aglomeração.

Dado que os coeficientes da Tabela 6 e 7 estão declinando, estima-se que as aglomerações no Nordeste desconcentraram a taxa de $3,17 \%$ ao ano entre 2007 e 2014.

Tabela 7 Principais índices de coaglomeração industrial no Nordeste

\begin{tabular}{|c|c|c|c|c|c|}
\hline$(r ; s)$ & Setor $r$ & Setor $s$ & 2007 & 2014 & $\Delta \gamma \mathrm{c}$ \\
\hline$(29 ; 33)$ & Veículos automotores & $\begin{array}{l}\text { Manutenção de máquinas e } \\
\text { equipamentos }\end{array}$ & 0,1713 & 0,0505 & $-0,1744$ \\
\hline$(20 ; 29)$ & Produtos químicos & Veículos automotores & 0,1150 & 0,0851 & $-0,0429$ \\
\hline$(20 ; 33)$ & Produtos químicos & $\begin{array}{l}\text { Manutenção de máquinas e } \\
\text { equipamentos }\end{array}$ & 0,0951 & 0,0410 & $-0,1201$ \\
\hline$(26 ; 29)$ & Informática e eletrônicos & Veículos automotores & 0,0886 & 0,0549 & $-0,0685$ \\
\hline$(22 ; 29)$ & Produtos de borracha e plástico & Veículos automotores & 0,0881 & 0,0600 & $-0,0549$ \\
\hline$(14 ; 21)$ & Vestuário e acessórios & Farmoquímicos e farmacêuticos & 0,0784 & 0,0461 & $-0,0759$ \\
\hline$(26 ; 33)$ & Informática e eletrônicos & $\begin{array}{l}\text { Manutenção de máquinas e } \\
\text { equipamentos }\end{array}$ & 0,0762 & 0,0293 & $-0,1366$ \\
\hline$(22 ; 33)$ & Produtos de borracha e plástico & $\begin{array}{l}\text { Manutenção de máquinas e } \\
\text { equipamentos }\end{array}$ & 0,0733 & 0,0245 & $-0,1565$ \\
\hline$(24 ; 29)$ & Metalurgia & Veículos automotores & 0,0573 & 0,0113 & $-0,2324$ \\
\hline$(21 ; 30)$ & Farmoquímicos e farmacêuticos & Transporte, exceto veículos & 0,0521 & $-0,0242$ & $x$ \\
\hline$(20 ; 26)$ & Produtos químicos & Informática e eletrônicos & 0,0514 & 0,0415 & $-0,0304$ \\
\hline$(20 ; 22)$ & Produtos químicos & Produtos de borracha e plástico & 0,0511 & 0,0451 & $-0,0176$ \\
\hline$(14 ; 30)$ & Vestuário e acessórios & Transporte, exceto veículos & 0,0496 & $-0,0298$ & $x$ \\
\hline$(24 ; 33)$ & Metalurgia & $\begin{array}{l}\text { Manutenção de máquinas e } \\
\text { equipamentos }\end{array}$ & 0,0433 & 0,0147 & $-0,1545$ \\
\hline$(24 ; 28)$ & Metalurgia & Máquinas e equipamentos & 0,0431 & 0,0119 & $-0,1834$ \\
\hline$(22 ; 26)$ & Produtos de borracha e plástico & Informática e eletrônicos & 0,0426 & 0,0247 & $-0,0776$ \\
\hline$(13 ; 14)$ & Têxteis & Vestuário e acessórios & 0,0405 & 0,0318 & $-0,0348$ \\
\hline$(21 ; 25)$ & Vestuário e acessórios & $\begin{array}{l}\text { Metal, exceto máquinas e } \\
\text { equipamentos }\end{array}$ & 0,0372 & 0,0185 & $-0,1000$ \\
\hline
\end{tabular}

Nota: Tabela organizada em ordem decrescente dos índices EGK 2007. 4 yc é a taxa de variação geométrica. Fonte: Resultado da pesquisa, elaboração própria. 


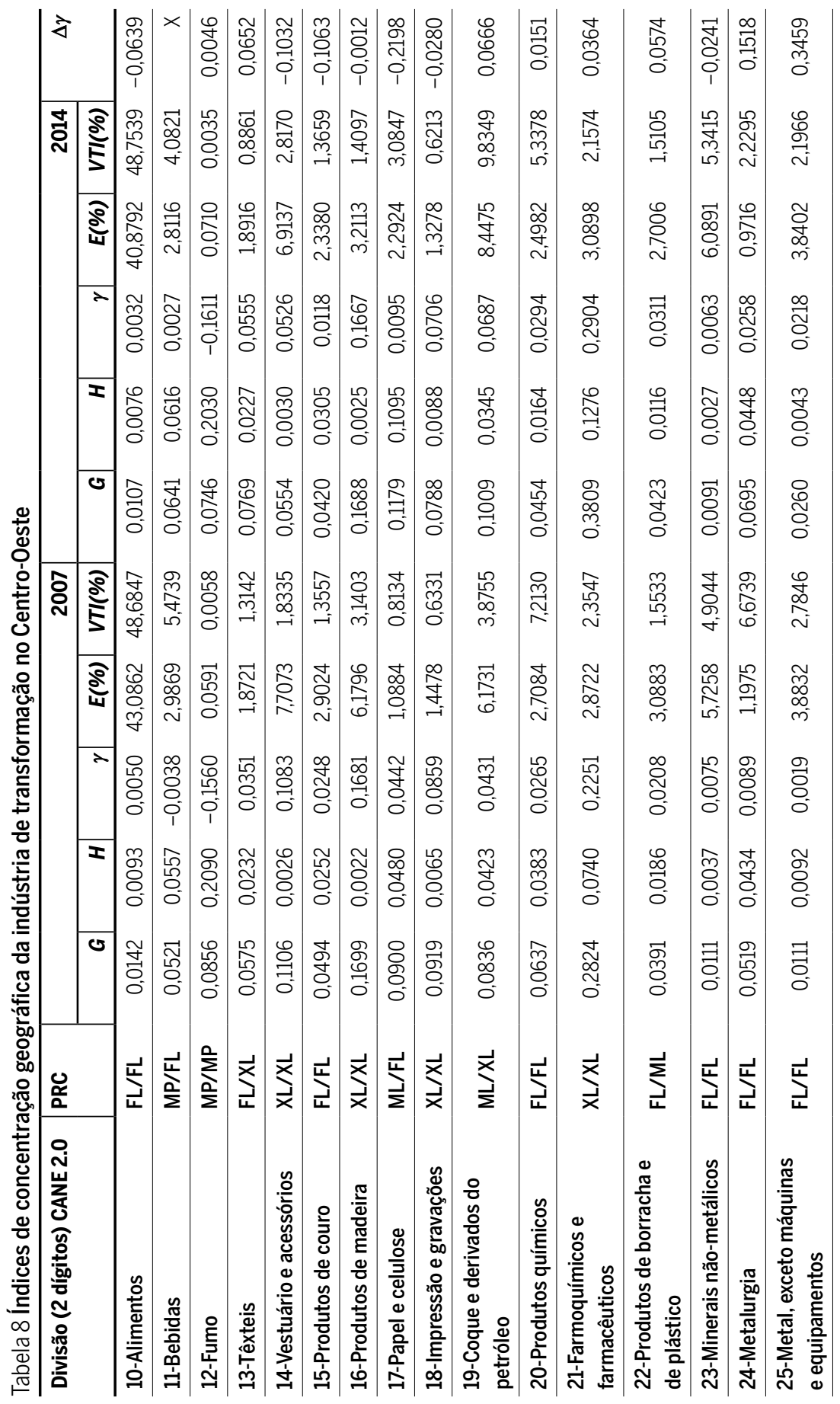




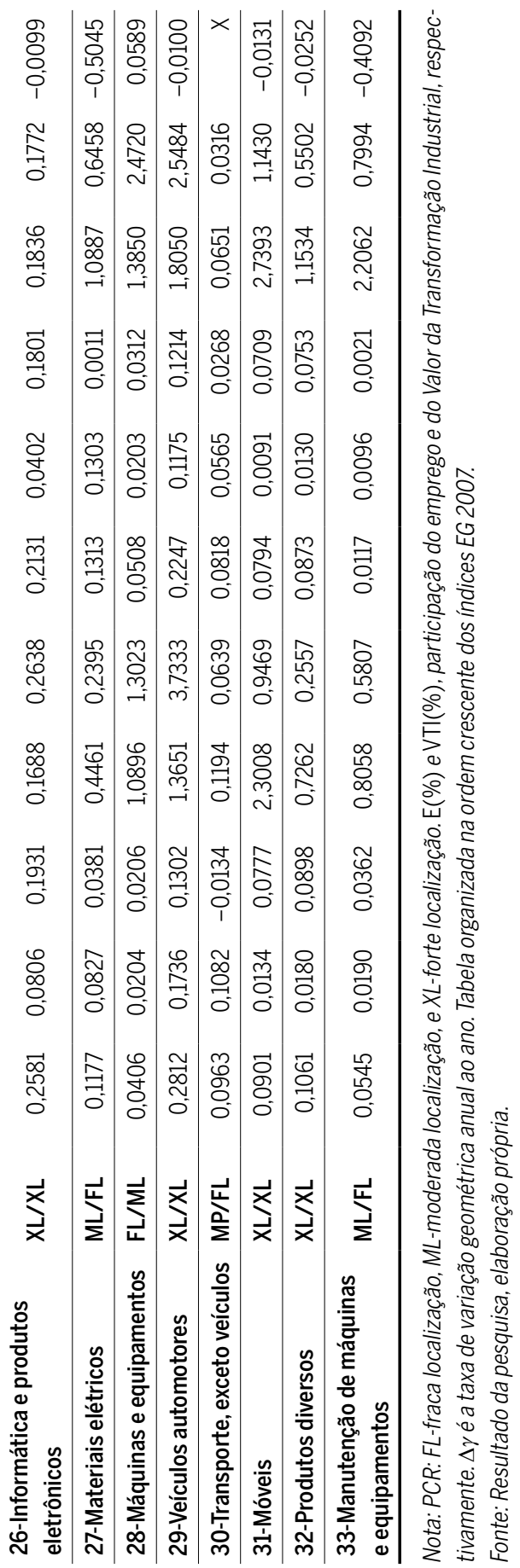




\subsubsection{Centro-Oeste}

Das três indústrias com as características de monopólio no ano inicial, dois redistribuíram a produção a ponto de gerar algum excedente positivo de economias de aglomeração (Tabela 8). Em termos de escala (participação no VTI), Bebidas é a mais importante do padrão e dá sinais de fortalecimento das conexões locais com Informática e produtos eletrônicos (Tabela 9).

As indústrias com fraca localização são as mais representativas no Centro-Oeste e responderam por 65,6\% do emprego e 75,8\% do VTI em 2007 (Tabela 8). A dinâmica desse padrão é dirigida pelo setor de Alimentos, que mostra visíveis sinais de desconcentração geográfica. A explicação para isso estaria nos ganhos de produtividade decorrentes da expansão da fronteira agropecuária, principal atividade econômica no Centro-Oeste. Dado que o setor é o mais importante para a formação do emprego e VTI, estima-se que ganhos de produtividade floresçam principalmente com a divisão do trabalho e especialização produtiva em torno da cadeia de Alimentos, uma vez que conexões horizontais com outros setores da economia não aparecem entre os principais índices de coaglomeração da Tabela 9.

\section{Figura 4 Função densidade $F_{\gamma}$ da indústria de transformação na região Centro-Oeste}
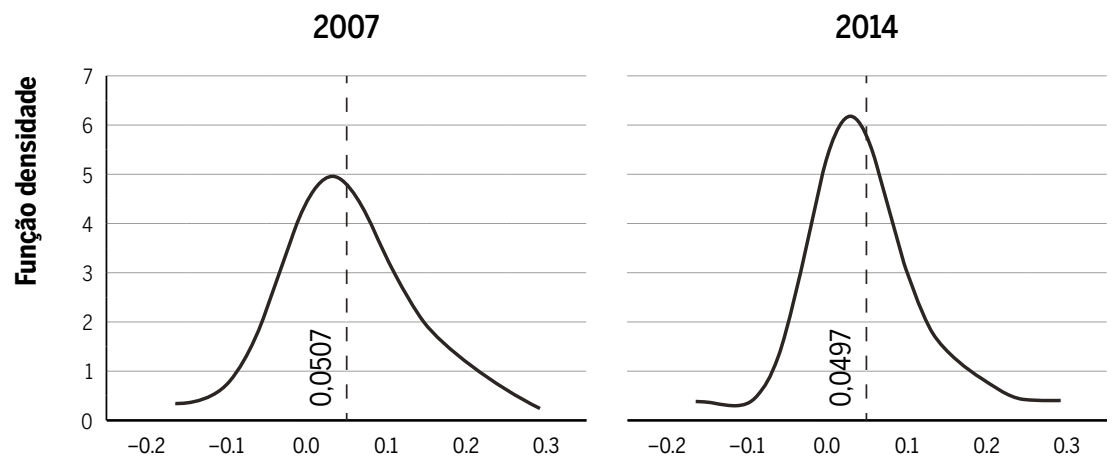

Nota: Linha tracejada é a média.

Fonte: Resultado da pesquisa, elaboração própria.

As indústrias com moderada localização são relativamente sensíveis a qualquer mudança locacional (Tabela 8). Veja o caso de Coque e derivados de petróleo e Papel e celulose, as mais representativas desse padrão. Ainda 
que esses setores estejam aumentando suas participações no emprego e no VTI regional, esse processo ocorreu sob dinâmicas espaciais diferentes: no primeiro caso, ganhos de escala surgiram com a concentração produtiva; ao passo que Papel e celulose mais do que dobrou sua participação no emprego e VTI regional, dispersando geograficamente suas atividades.

À direita da média de $F_{\gamma}$, é possível identificar oito indústrias fortemente localizadas (Figura 4 e Tabela 8). Tal como no contexto nacional, a polarização de algumas indústrias baseadas em vantagens competitivas (Farmoquímicos e farmacêuticos e Informática e eletrônicos) pode estar sendo favorecida pela atração de mão de obra especializada para o interior da região.

Tabela 9 Principais índices de coaglomeração industrial no Centro-Oeste

\begin{tabular}{l|l|l|r|r|r}
\hline $\mathbf{( r ; \boldsymbol { s } )}$ & Setor $\boldsymbol{r}$ & Setor $\boldsymbol{s}$ & $\mathbf{2 0 0 7}$ & $\mathbf{2 0 1 4}$ & $\mathbf{\Delta} \mathbf{c}$ \\
\hline $\mathbf{( 1 2 , 2 6 )}$ & Fumo & Informática e eletrônicos & 0,1462 & 0,1247 & $-0,0227$ \\
\hline $\mathbf{( 1 8 , 2 6 )}$ & Impressão e gravações & Informática e eletrônicos & 0,1418 & 0,0990 & $-0,0512$ \\
\hline $\mathbf{( 1 4 , 3 2 )}$ & Vestuário e acessórios & Produtos diversos & 0,1002 & 0,0596 & $-0,0743$ \\
\hline $\mathbf{( 1 7 , 2 1 )}$ & Papel e celulose & Farmoquímicos e farmacêuticos & 0,1001 & 0,0385 & $-0,1365$ \\
\hline $\mathbf{( 1 4 , 2 1 )}$ & Vestuário e acessórios & Farmoquímicos e farmacêuticos & 0,0989 & 0,0518 & $-0,0924$ \\
\hline $\mathbf{( 1 4 , 1 7 )}$ & Vestuário e acessórios & Papel e celulose & 0,0947 & 0,0568 & $-0,0731$ \\
\hline $\mathbf{( 2 6 , 3 3 )}$ & Informática e eletrônicos & Manutenção de maq./equip. & 0,0904 & 0,0333 & $-0,1426$ \\
\hline $\mathbf{( 3 1 , 3 2 )}$ & Móveis & Produtos diversos & 0,0879 & 0,0760 & $-0,0208$ \\
\hline $\mathbf{( 1 7 , 3 2 )}$ & Papel e celulose & Produtos diversos & 0,0866 & 0,0679 & $-0,0348$ \\
\hline $\mathbf{( 1 2 , 1 8 )}$ & Fumo & Impressão e gravações & 0,0823 & 0,0721 & $-0,0188$ \\
\hline $\mathbf{( 1 4 , 3 1 )}$ & Vestuário e acessórios & Móveis & 0,0775 & 0,0479 & $-0,0687$ \\
\hline $\mathbf{( 1 1 , 2 6 )}$ & Bebidas & Informática e eletrônicos & 0,0744 & 0,0980 & 0,0395 \\
\hline $\mathbf{( 1 7 , 3 1 )}$ & Papel e celulose & Móveis & 0,0691 & 0,0589 & $-0,0228$ \\
\hline $\mathbf{( 1 8 , 3 1 )}$ & Impressão e gravações & Móveis & 0,0648 & 0,0564 & $-0,0197$ \\
\hline $\mathbf{( 2 1 , 3 2 )}$ & Farmoquímicos e farmacêuticos & Produtos diversos & 0,0624 & 0,0140 & $-0,2132$ \\
\hline $\mathbf{( 1 3 , 2 7 )}$ & Têxteis & Materiais elétricos & 0,0610 & 0,0628 & 0,0042 \\
\hline $\mathbf{( 2 7 , 3 3 )}$ & Materiais elétricos & Manutenção de maq./equip. & 0,0593 & $-0,0017$ & X \\
\hline $\mathbf{( 2 6 , 2 8 )}$ & Informática e eletrônicos & Máquinas e equipamentos & 0,0584 & 0,0488 & $-0,0257$ \\
\hline & & & &
\end{tabular}

Nota: Tabela organizada em ordem decrescente dos índices EGK 2007. yc éa taxa de variação geométrica. Fonte: Resultado da pesquisa, elaboração própria.

No entanto, há um grupo composto por quatro indústrias (Vestuário e acessórios, Têxteis, Móveis e Impressão e gravações), que devido às suas características estruturais não deveriam ser tão concentradas na produção. Além 
das razões mencionadas anteriormente, é provável que a polarização seja reforçada pelas conexões fornecedor-produto estabelecidas entre firmas diferenciadas, uma vez que todas frequentam os principais índices de coaglomeração no Centro-Oeste, conforme mostra a Tabela 9.

Examinando a taxa de variação do índice de EG na Tabela 8, percebe-se que a maioria das indústrias com moderada ou forte localização desconcentraram suas atividades. Então por que a média da função densidade (Figura 4) se manteve inalterada, levando a ausência de mudanças nos padrões de concentração regional?

A resposta está na concentração das indústrias com fraca localização, que tiveram sua densidade aumentada pelas aglomerações (Bebidas e Transporte, exceto veículos), excedendo os monopólios. Isto fica visível da Figura 4, que mostra maior massa em 2014. Dito de outra forma, as aglomerações criadas pelas indústrias com fraca localização e a deterioração dos monopólios compensaram as deseconomias de aglomeração dos setores mais dinâmicos da economia regional. Portanto, ainda que alguns setores estejam desmobilizando, não se pode falar num retrocesso pleno das aglomerações no Centro-Oeste.

\subsection{Padrões de localização nas regiões centrais}

A estrutura industrial nos centros tem como principal característica a integralidade setorial-regional, o que possibilita a diversificação das cadeias produtivas. As principais externalidades são dinâmicas e se formam com a inovação tecnológica, com isso o monopólio homogêneo torna-se uma estrutura frágil, irrelevante para o desenvolvimento regional. Nos ambientes urbanos, as inovações tecnológicas constituem a principal fonte de retornos crescentes e atuam como forças de atração para novas empresas, novos produtos e processos. Os resultados das regiões Sul e Sudeste mostram que as conexões intersetoriais mais promissoras surgem da interação entre firmas fortemente localizadas, mais especificamente, entre setores que tradicionalmente recorrem à inovação tecnológica como estratégia competitiva. Os resultados encontrados aqui corroboram com os de outros autores que estudaram o tema (Lemos et al., 2005; Silva; Suzigan, 2014).

As Tabelas 10 e 12 demonstram os índices de concentração geográfica da indústria de transformação nas regiões Sul e Sudeste, respectivamente; 
as Tabelas 11 e 13 demonstram suas principais coaglomerações industriais; e as Figuras 5 e 6 , exibem as respectivas funções densidade.

\subsubsection{Sul}

Em termos de formação de emprego (25,7\%) e do VTI (20,1\%), o Sul é a segunda região mais importante do país onde a distribuição espacial da atividade industrial é menos desigual. ${ }^{3}$ Existem, nessa região, cinco polos importantes que juntos absorveram 43\% do emprego regional em 2007. Porto Alegre, no Rio Grande do Sul, é a maior aglomeração regional e a quarta maior do país, onde se destaca a indústria de Veículos automotores, Produtos de couro e bens complementares produzidos em Caxias do Sul, a 130 km de Porto Alegre. Curitiba, no Paraná, é a segunda maior aglomeração do Sul e se destaca pela qualidade industrial medida pela participação de firmas que inovam e diferenciam produto (Lemos et al., 2005). Joinville-Blumenau, em Santa Catarina, formam duas aglomerações interligadas, onde a indústria concentrou-se em torno de Têxteis e Vestuário e acessórios. A região Sul é bem articulada por um sistema de transporte que facilita a mobilidade de recursos, de modo que a indústria com fraca localização é a mais representativa em termos de formação do VTI $(56,9 \%)$ e de emprego (54,2\%), conforme mostra a Tabela 10.

No padrão com fraca localização, três indústrias representativas e tecnologicamente diferenciadas (Máquinas e equipamentos, Coque e derivados do petróleo e Alimentos) obtiveram ganhos de escala desconcentrando a produção. Alimentos chama atenção pela aparente relação positiva entre ganhos de produtividade e mobilidade regional, uma vez que o VTI cresceu cerca de quatro vezes mais que o emprego. Tal como no Centro-Oeste, esses ganhos podem estar vinculados ao agronegócio, atividade capaz de induzir a mobilidade de fornecedores Máquinas e equipamentos e outros bens complementares para o interior da região Sul. A despeito das causas dessa mobilidade, o fato é que as principais indústrias com fraca localização e todas aquelas consideradas moderadamente localizadas estão expandindo geograficamente suas atividades no Sul do país (Tabela 12).

3 Com base no emprego agregado para a microrregião em 2007, verificou-se que o Gini locacional da região Sul foi 0,658; da região Sudeste foi 0,734; enquanto para o Brasil foi 0,772 . 


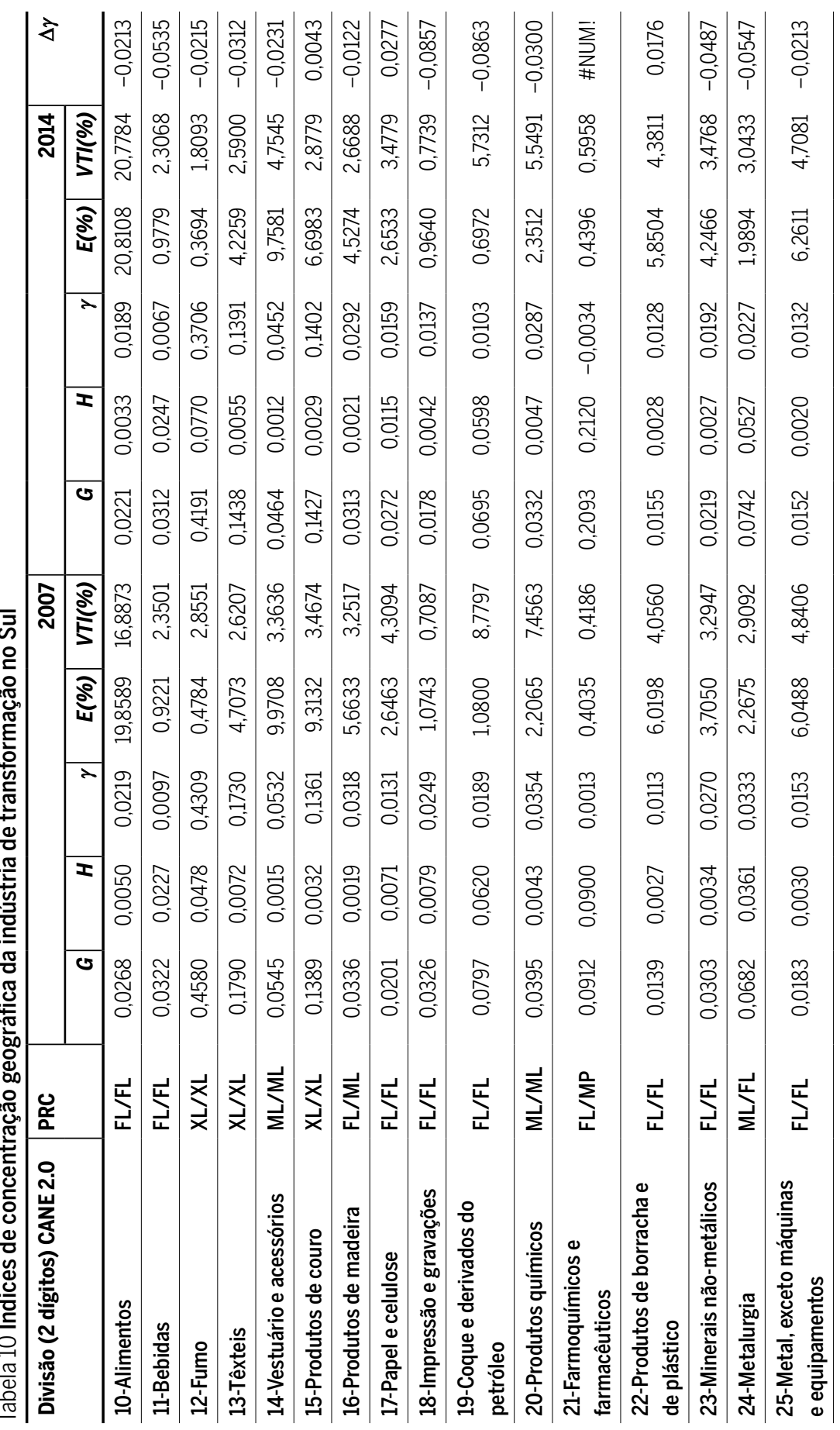




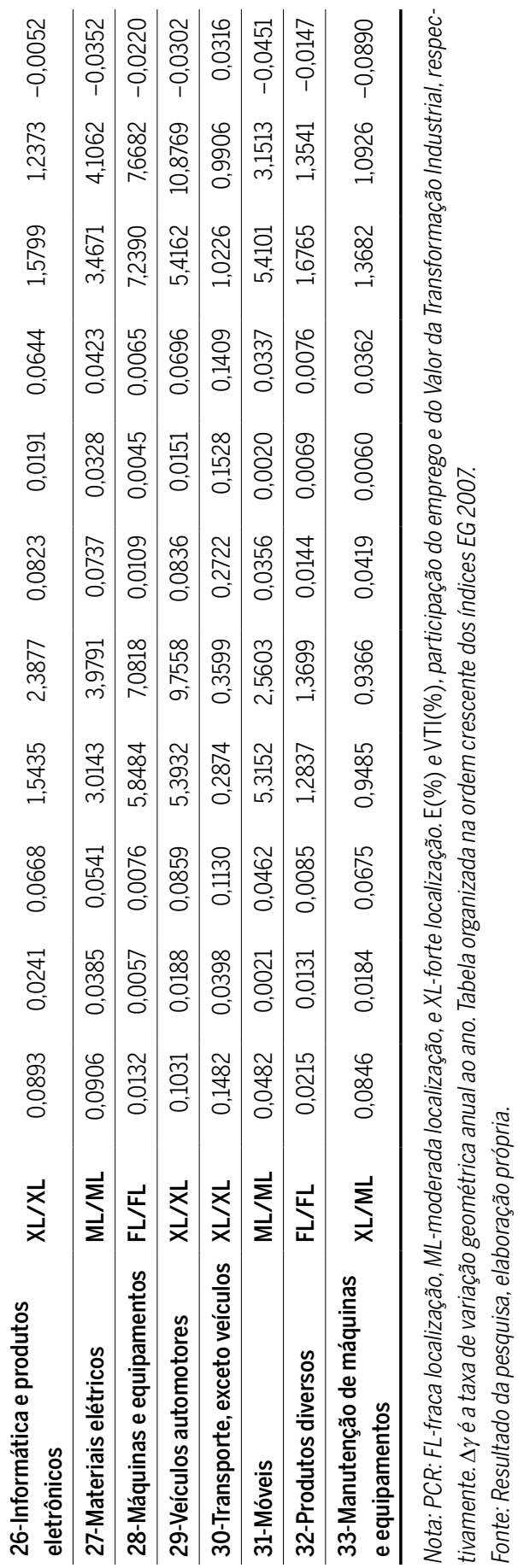


Os resultados da Tabela 10 permitem inferir acerca da presença de indústrias (Informática e eletrônicos, Veículos automotores e Produtos de couro) cujo poder de concentração vincula-se às economias de urbanização, representadas pelo tamanho do mercado e através do intercâmbio tecnológico dele derivado, geralmente transmitido pelo uso de recursos comuns (um mercado de trabalho qualificado é um bom exemplo) ou pelo acesso de bens e serviços reunidos numa ampla rede de fornecedores especializados. Não por acaso, essas indústrias aparecem com frequência entre os principais índices de coaglomeração (Tabela 11), indicando que a existência de fortes laços intersetoriais contribui para a polarização de setores com características específicas. A Tabela 11 destaca, ainda, a concentração do par (Têxteis e Vestuário e acessórios), reforçando o argumento de que a concentração industrial em Joinville-Blumenau se apoia nos retornos crescentes derivados dessas atividades.

Figura 5 Função densidade $F_{\gamma}$ da indústria de transformação no Sul
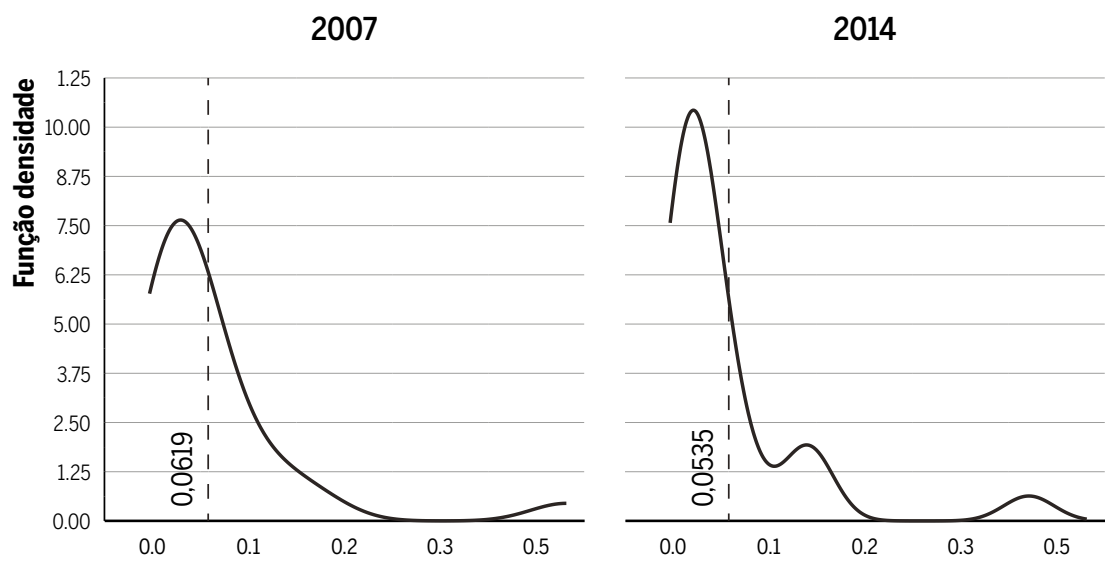

Nota: Linha tracejada é a média.

Fonte: Resultado da pesquisa, elaboração própria.

Na Figura 5, percebe-se que a média das aglomerações retraiu no Sul entre 2007 e 2014, o que condiz com o diagnóstico de mudanças nos padrões de concentração regional. Percebe-se, também, que a densidade das aglomerações cresceu à esquerda da média, indicando que os setores que expandiram geograficamente a produção foram àqueles classificados com fraca e moderada localização no ano inicial, principalmente. Pela taxa de 
variação do índice EG na Tabela 10, pode-se concluir que a desconcentração industrial no Sul segue de forma equilibrada entre setores, evoluindo lentamente, em torno de $2,1 \%$ a.a.

Tabela 11 Principais índices de coaglomeração industrial no Sul

\begin{tabular}{llllr|r|r}
\hline $\mathbf{( r ; s )}$ & Setor $\boldsymbol{r}$ & Setor $\boldsymbol{s}$ & $\mathbf{2 0 0 7}$ & $\mathbf{2 0 1 4}$ & $\mathbf{\Delta} \mathbf{c}$ \\
\hline $\mathbf{( 1 3 , 1 4 )}$ & Têxteis & Vestuário e acessórios & 0,0831 & 0,0668 & $-0,0311$ \\
\hline $\mathbf{( 2 6 , 3 3 )}$ & Informática e eletrônicos & Manutenção de máq./equip. & 0,0761 & 0,0510 & $-0,0572$ \\
\hline $\mathbf{( 2 4 , 2 7 )}$ & Metalurgia & Materiais elétricos & 0,0635 & 0,0656 & 0,0047 \\
\hline $\mathbf{( 1 5 , 3 3 )}$ & Produtos de couro & Manutenção de máq./equip. & 0,0529 & 0,0325 & $-0,0695$ \\
\hline $\mathbf{( 2 6 , 2 9 )}$ & Informática e eletrônicos & Veículos automotores & 0,0529 & 0,0348 & $-0,0598$ \\
\hline $\mathbf{( 1 8 , 2 6 )}$ & Impressão e gravações & Informática e eletrônicos & 0,0432 & 0,0266 & $-0,0695$ \\
\hline $\mathbf{( 1 1 , 2 9 )}$ & Bebidas & Veículos automotores & 0,0407 & 0,0303 & $-0,0420$ \\
\hline $\mathbf{( 2 0 , 2 6 )}$ & Produtos químicos & Informática e eletrônicos & 0,0406 & 0,0336 & $-0,0267$ \\
\hline $\mathbf{( 1 1 , 2 6 )}$ & Bebidas & Informática e eletrônicos & 0,0390 & 0,0301 & $-0,0370$ \\
\hline $\mathbf{( 2 0 , 3 3 )}$ & Produtos químicos & Manutenção de máq./equip. & 0,0362 & 0,0245 & $-0,0561$ \\
\hline $\mathbf{( 1 8 , 3 3 )}$ & Impressão e gravações & Manutenção de máq./equip. & 0,0331 & 0,0146 & $-0,1164$ \\
\hline $\mathbf{( 1 8 , 2 9 )}$ & Impressão e gravações & Veículos automotores & 0,0329 & 0,0188 & $-0,0801$ \\
\hline $\mathbf{( 2 5 , 2 9 )}$ & Metal, exceto maq./equip. & Veículos automotores & 0,0324 & 0,0282 & $-0,0202$ \\
\hline $\mathbf{( 1 1 , 3 3 )}$ & Bebidas & Manutenção de máq./equip. & 0,0306 & 0,0208 & $-0,0553$ \\
\hline
\end{tabular}

Nota: Tabela organizada em ordem decrescente dos índices EGK2007. 4 c éa taxa de variação geométrica. Fonte: Resultado da pesquisa, elaboração própria.

\subsubsection{Sudeste}

No Sudeste estão localizados os principais polos industriais do país. A AMSP é o principal polo industrial do país e exerce forte influência sobre cidades médias localizadas no seu entorno, no interior do estado de São Paulo e demais regiões. Confere-se à AMSP o papel de "lugar-central" (LEMOS et al., 2005), pois de lá se formou uma extensa aglomeração ao longo de um espaço contíguo, que atualmente apresenta níveis avançados de integração e complementaridade produtiva. Além dessa aglomeração primaz, o Sudeste possui outros polos importantes como a indústria metalmecânica e petrolífera no Rio de Janeiro, e a aglomeração de Belo Horizonte, o terceiro maior centro industrial do país, só atrás da AMSP e de Campinas, no noroeste de São Paulo. 


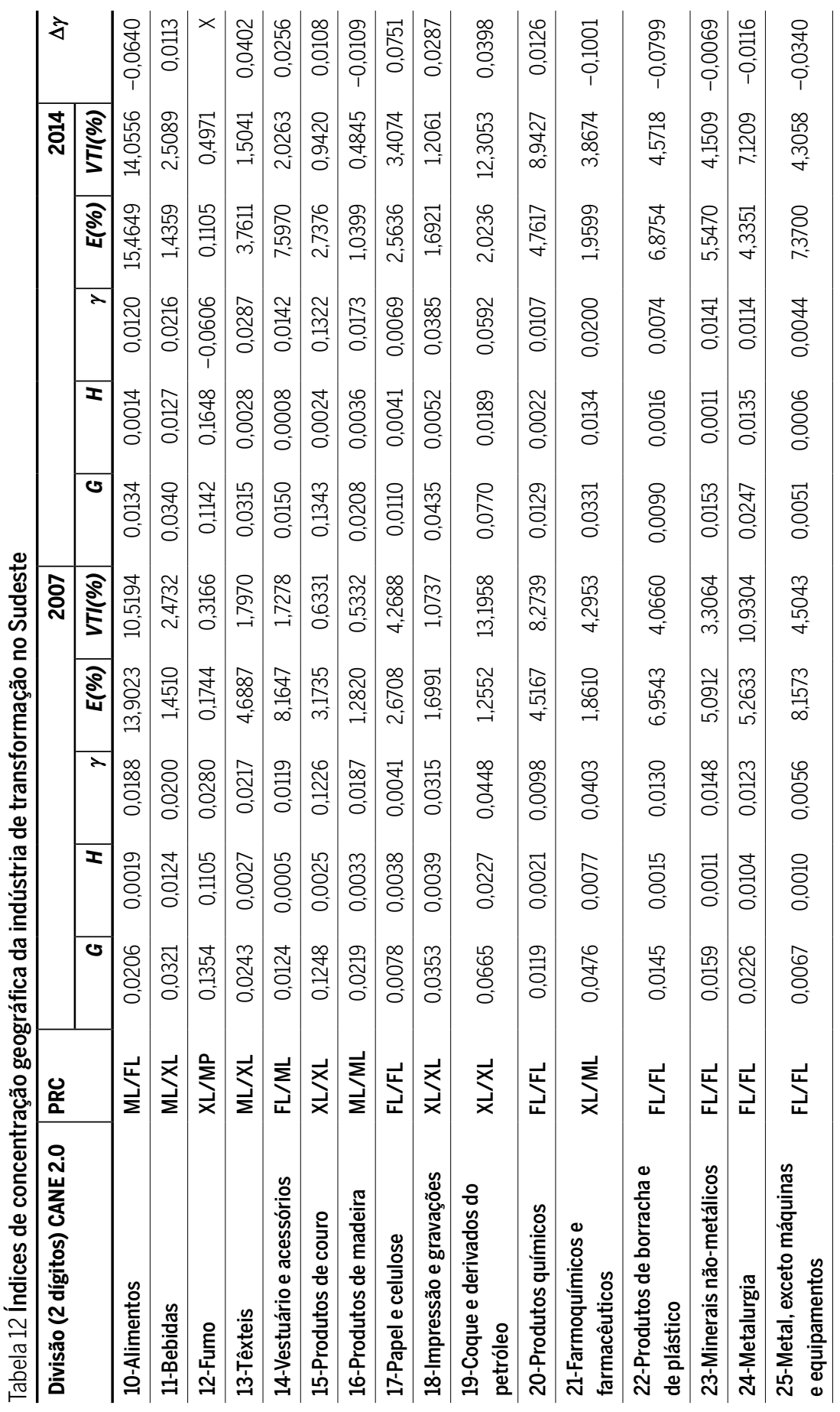




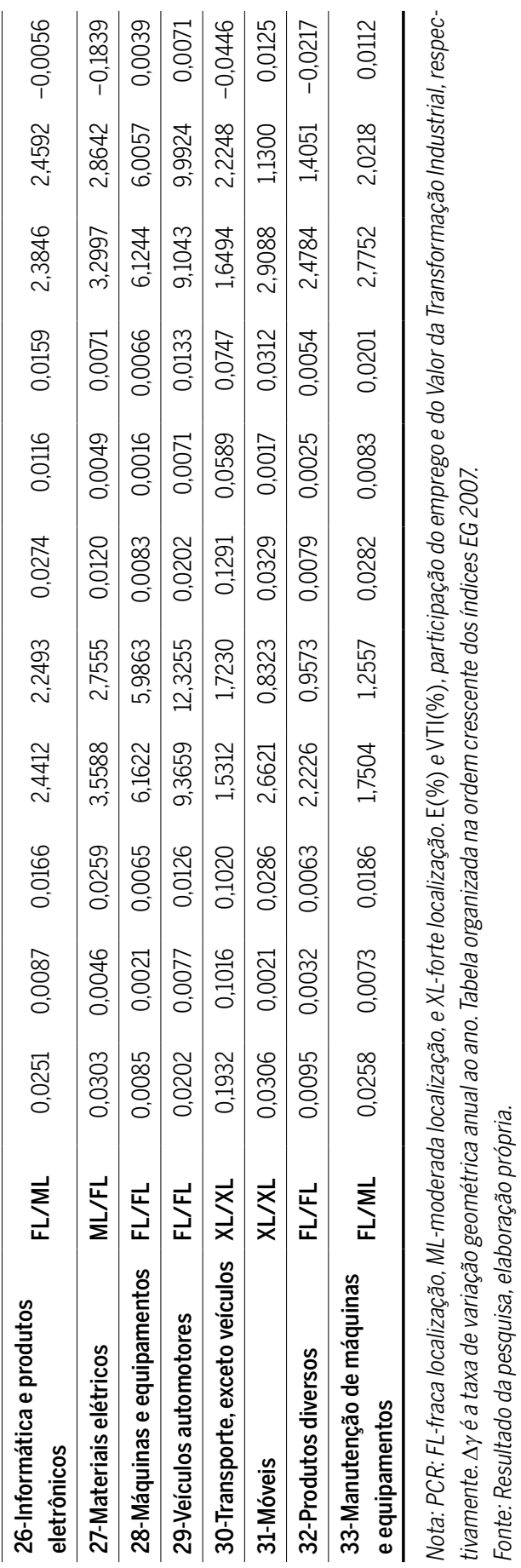


A forte influência na formação do emprego e produto industrial torna os padrões de concentração do Sudeste, os mais representativos no contexto nacional. Dos 12 setores identificados com fraca localização em 2007, apenas Veículos automotores e Informática e eletrônicos não se enquadram em padrão equivalente no contexto nacional (Tabela 14) e, diferentemente da desconcentração atestada para o resto do Brasil, não há para a região indícios de mudanças nas taxas de aglomeração dessas indústrias. A propósito, a geografia econômica no Sudeste é marcada pela fraca concentração dos produtores de bens de capital (Metal, exceto máquinas e equipamentos, Máquinas e equipamentos e Manutenção de máquinas e equipamentos) e duráveis com alto valor adicionado (Veículos automotores e Informática e eletrônicos). Essa característica favorece a articulação de políticas de fomento ao desenvolvimento regional, pois essas indústrias costumam exercer influência sobre a localização de bens e serviços complementares.

Figura 6 Função densidade $F_{\gamma}$ da indústria de transformação no Sudeste
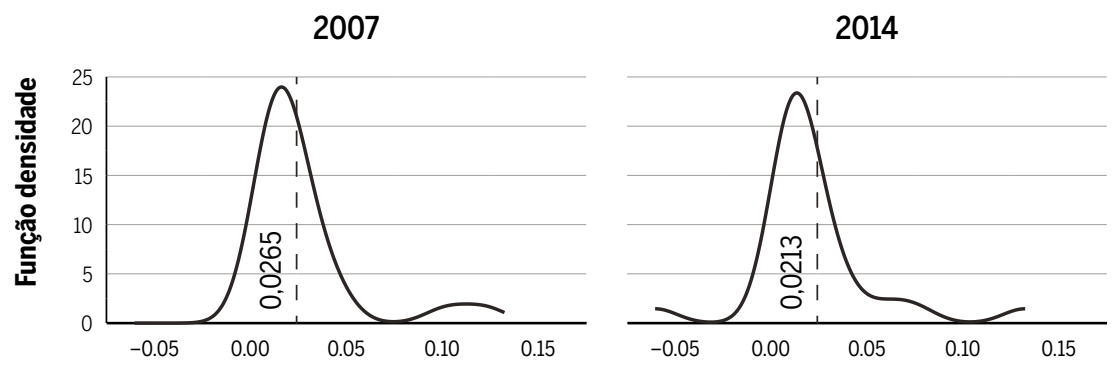

Nota: Linha tracejada é a média.

Fonte: Resultado da pesquisa, elaboração própria.

A Tabela 12 demonstra que apenas 2 indústrias fracamente localizadas (Papel e celulose e Vestuário e acessórios) seguem em forte tendência concentradora. Vestuário e acessórios é um caso interessante, pois sua estrutura é composta por um grande grupo de pequenas firmas (índice de Herfindahl) que concentraram a produção em poucas microrregiões, alterando o padrão locacional. As taxas de aglomeração das demais indústrias desse padrão exibem valores que se aproximam de zero ou são negativas, indicando dispersão geográfica. 
Situação semelhante é encontrada no padrão moderada localização, composto por cinco indústrias tecnologicamente diferenciadas e sensíveis a qualquer mudança locacional. Assim como no Sul do país, a indústria de Alimentos se destaca pelos ganhos de produtividade que acompanharam a expansão geográfica da atividade, considerando que o aumento na participação do VTI foi superior ao da mão de obra. Materiais elétricos é um setor que apresenta sinais de mobilidade regional, seguindo a tendência nacional antes diagnosticada.

Tabela 13 Principais índices de coaglomeração industrial no Sudeste

\begin{tabular}{lllrrrr}
\hline $\mathbf{( r ; s )}$ & Setor $\boldsymbol{r}$ & Setor $\boldsymbol{s}$ & $\mathbf{2 0 0 7}$ & $\mathbf{2 0 1 4}$ & $\mathbf{\Delta} \mathbf{c}$ \\
\hline $\mathbf{( 1 2 , 1 8 )}$ & Fumo & Impressão e gravações & 0,0441 & 0,0302 & $-0,0539$ \\
\hline $\mathbf{( 1 1 , 3 0 )}$ & Bebidas & Transporte, exceto veículos & 0,0404 & 0,0324 & $-0,0314$ \\
\hline $\mathbf{( 1 5 , 1 9 )}$ & Produtos de couro & Coque e derivados do petróleo & 0,0365 & 0,0211 & $-0,0780$ \\
\hline $\mathbf{( 1 2 , 2 1 )}$ & Fumo & Farmoquímicos e farmacêuticos & 0,0308 & 0,0155 & $-0,0982$ \\
\hline $\mathbf{( 1 9 , 3 0 )}$ & Coque e derivados do petróleo & Transporte, exceto veículos & 0,0296 & 0,0534 & 0,0841 \\
\hline $\mathbf{( 1 8 , 2 1 )}$ & Impressão e gravações & Farmoquímicos e farmacêuticos & 0,0289 & 0,0273 & $-0,0078$ \\
\hline $\mathbf{( 1 0 , 1 9 )}$ & Alimentos & Coque e derivados do petróleo & 0,0266 & 0,0150 & $-0,0814$ \\
\hline $\mathbf{( 1 0 , 1 5 )}$ & Alimentos & Produtos de couro & 0,0226 & 0,0150 & $-0,0581$ \\
\hline $\mathbf{( 2 1 , 2 2 )}$ & Farmoquímicos e farmacêuticos & Produtos de borracha e de plástico & 0,0216 & 0,0134 & $-0,0680$ \\
\hline $\mathbf{( 1 1 , 1 9 )}$ & Bebidas & Coque e derivados do petróleo & 0,0215 & 0,0341 & 0,0660 \\
\hline $\mathbf{( 1 2 , 3 3 )}$ & Fumo & Manutenção de máq./equip. & 0,0208 & 0,0247 & 0,0242 \\
\hline $\mathbf{( 1 2 , 2 0 )}$ & Fumo & Produtos químicos & 0,0205 & 0,0130 & $-0,0650$ \\
\hline $\mathbf{( 1 1 , 1 2 )}$ & Bebidas & Fumo & 0,0202 & 0,0140 & $-0,0518$ \\
\hline $\mathbf{( 1 2 , 3 0 )}$ & Fumo & Transporte, exceto veículos & 0,0201 & 0,0200 & $-0,0002$ \\
\hline
\end{tabular}

Nota: Tabela organizada em ordem decrescente dos índices EGK 2007. $\gamma$ c é a taxa de variação geométrica. Fonte: Resultado da pesquisa, elaboração própria.

Verifica-se no padrão forte localização que as taxas de aglomeração de duas indústrias importantes (Farmoquímicos e farmacêuticos e Transporte, exceto veículos) estão declinando rapidamente. Como discutido anteriormente, as razões estariam na perda de competitividade sistêmica, com efeitos mais visíveis no Sudeste, onde as indústrias mais dinâmicas estão concentradas. Não é demais lembrar que as indústrias citadas destacam-se pelo alto grau de esforço inovador e são vetores de difusão tecnológica para outros setores da economia (Silva; Suzigan, 2014). 
Mais evidências podem ser encontradas na Tabela 13, com os principais índices de coaglomeração. Ao examiná-la, percebe-se que indústrias com padrões tecnológico diferenciados podem estabelecer um padrão colocalização determinado pelo compartilhamento de recursos comuns, sejam eles tangíveis (oferta de mão de obra especializada) ou intangíveis (spillovers tecnológicos). Um exemplo disso é a indústria de Fumo, cuja localização é influenciada por vários outros setores diferentes.

Segundo a Tabela 12, Fumo migrou para monopólio entre 2007 e 2014. Considerando que o índice Hirschman-Herfindahl aumentou consideravelmente, o monopólio deve ter surgido com a mobilidade de recursos em torno de uma planta com forte presença de economia de escala. Essa mudança fica visível em $F_{\gamma}$, próximo $\gamma=-0.05$ em 2014 (Figura 6). Tomando a média da função densidade, estima-se que a indústria no Sudeste está desconcentrando a uma taxa de $3,1 \%$ a.a.

\section{Considerações finais}

Este artigo analisou mudanças nos padrões de concentração geográfica da indústria de transformação brasileira entre 2007-2014. Para tanto, estimaram-se funções densidade $F_{\gamma}$ para o índice de aglomeração Ellison e Glaeser (1997), calculado entre divisões (2 dígitos) da CNAE 2.0, em dois contextos espaciais diferentes: o primeiro correspondente ao território nacional; e o segundo envolveu as regiões Norte, Nordeste, Centro-Oeste, Sul e Sudeste. A análise foi completada com o índice de coaglomeração de Ellison, Glaeser e Kerr (2007).

Constatou-se que a função densidade $F_{\gamma}$ estimada para o território nacional é assimétrica e assemelha-se ao padrão lognormal definido por Ellison e Glaeser (1997). Além disso, cerca de 50\% das aglomerações industriais de padrão fraca localização são compostas por firmas tradicionais e produtores de commodities com baixo poder de concentração, principalmente; uma minoria delas produz bens de capital.

Percebeu-se que a indústria tradicional vem aumentando seu peso tanto na formação do emprego quanto no VTI. Por outro lado, as aglomerações dos setores mais dinâmicos (bens de capital e bens de consumo duráveis) enfrentam um processo de deterioração que compromete a formação do emprego e o VTI. Em termos comparativos, esse resultado contrasta com 
a análise de grupamento aplicada por Saboia, Kubrusly e Barros (2014) no nível das divisões da indústria brasileira no período 2003-2011.

Em termos regionais, verificou-se que os parâmetros (média e variância) de $F_{\gamma}$ estimados para o Norte, Nordeste, Sudeste e Sul foram sensivelmente alterados, indicando que a desconcentração geográfica é um processo que evoluiu sob padrões diferentes. Por exemplo, a expansão dos monopólios nas regiões periféricas foi determinante para reduzir a taxa média de aglomeração nas regiões Norte e Nordeste. No entanto, esse tipo de estrutura não é capaz de promover mudanças locacionais significativas nas regiões centrais do Sul e Sudeste do país. Ademais, não há evidências de mudanças nos padrões de concentração industrial no Centro-Oeste.

Um dos principais resultados remete à identificação de um grupo com seis indústrias dinâmicas que produzem bens de capital e bens duráveis, fortemente localizado na Zona Franca de Manaus, mas que enfrenta um retrocesso problemático, que evolui rapidamente e comprometeu a formação de emprego e do VTI no Norte. No Nordeste, por sua vez, a situação é menos crítica, pois a deterioração das aglomerações dinâmicas concentradas no polo de Camaçari-Bahia foi atenuada pelo desempenho da indústria tradicional. Assim como no Norte ( $-4,7 \%$ a.a.), as taxas de aglomeração no Nordeste ( $-3,2 \%$ a.a.) estão declinando, porém de forma mais lenta e aproximando-se da média nacional ( $-2,7 \%$ a.a.).

A desconcentração no Sul segue de forma lenta $(-2,1 \%$ a.a.) e equilibrada entre setores e foi dirigida pela expansão produtiva das indústrias com fraca-moderada localização. No Sudeste, entretanto, esse processo não é equilibrado entre setores, pois embora a taxa média de aglomeração ( $-3,1 \%$ a.a.) se aproxime do padrão nacional ( $-2,7 \%$ a.a.), há alta variação entre os padrões locacionais. Contudo, a desconcentração tem beneficiado microrregiões no Sul do país, principalmente, corroborando os resultados de outros estudos (Saboia, 2013; Sobrinho; Azzoni, 2016). Além disso, a geografia econômica no Sudeste é marcada pela fraca concentração das indústrias de bens de capital e de bens duráveis, o que favorece a articulação de políticas de desenvolvimento regional.

Existem diferentes opções de política pública, de caráter macroeconômico ou de cunho industrial, que podem funcionar como forças de atração, ou mesmo que atuem no sentido de diminuir a dispersão das atividades produtivas, ambas direcionadas a reforçar os aglomerados industriais. Embora, não seja objeto deste estudo, vale mencionar que a 
própria heterogeneidade da estrutura produtiva, marcada por diferentes setores que concorrem como forças de atração internas nas grandes regiões brasileiras, sugere que essas políticas precisam ser diferenciadas em nível regional. Assim, por exemplo, nas regiões periféricas com uma concentração industrial mais dependente de firmas tradicionais e de produtores de commodities, espera-se que as aglomerações industriais sejam mais sensíveis às políticas de desonerações fiscais e tributárias, o que não ocorre, necessariamente, nas regiões com um padrão tecnológico mais desenvolvido, como a indústria de bens de capital e de bens duráveis. No caso da região Sudeste, as políticas de Ciência e Tecnologia (C\&T) ou que reforcem o acúmulo de capital humano (e seus transbordamentos), poderiam ter resultados significativos em setores como Farmoquímicos e farmacêuticos e de Transporte, concorrendo tanto para aumentar a produtividade e, consequentemente, a competitividade desses setores, como atrair outros segmentos industriais, com os quais guardam maior grau de interdependência setorial, como a indústria de produtos de borracha e de plástico e a indústria de produtos químicos.

Considerando as limitações de uma análise construída a partir de dois cortes, não se pode afirmar absolutamente que as mudanças diagnosticadas são irreversíveis ou de caráter estrutural. Porém, a metodologia serviu para demonstrar que durante o ciclo recessivo as aglomerações do Norte e Nordeste foram as que mais se deterioraram, ao passo que as do Sul e Sudeste foram as menos afetadas.

\section{Referências}

AZZONI, C. R. Indústria e reversão da polarização no Brasil. São Paulo: Instituto de Pesquisas Econômicas, 1986. v. 58.

BONELLI, R.; PESSOA, S.; MATOS, S. Desindustrialização no Brasil: fatos e interpretação. In: BACHA, E.; BOLLE, M. B. D. (Ed.). O futuro da indústria no Brasil: desindustrialização em debate. Rio de Janeiro: Civilização Brasileira, 2013. v. 1, cap. 1, p. 45-80.

BRESSER-PEREIRA, L. C. Doença holandesa e sua neutralização: uma abordagem ricardiana. Revista de Economia Política, v. 28, n. 1, p. 47-71, 2007.

CANO, W. Desconcentração produtiva regional do Brasil: 1970-2005. São Paulo: Editora UNESP, 2007.

CURADO, M. L.; CURADO, T. Uma estimativa dos custos fiscais da política industrial recente (2004-2016). Texto para discussão n. 2.248. Brasília: Instituto de Pesquisa Econômica 
Aplicada-Ipea, 2016.

DINIZ, C. Desenvolvimento poligonal no Brasil: nem concentração, nem contínua polarização. Nova Economia, Belo Horizonte, v. 3, n. 1, 1993.

DINIZ, C. C.; CROCCO, M. A. Reestruturação econômica e impacto regional: o novo mapa da indústria brasileira. Nova economia. Economics Department, Universidade Federal de Minas Gerais (Brazil), v. 6, n. 1, p. 77-103, 1996.

EFRON, B.; TIBSHIRANI, R. J. An introduction to the bootstrap, monographs on statistics and applied probability, v. 57. New York and London: Chapman and Hall/CRC, 1993.

ELLISON, G.; GLAESER, E. L. Geographic concentration in us manufacturing industries: a dartboard approach. Journal of Political Economic, v. 1, n. 5, p. 889-972, 1997.

ELLISON, G.; GLAESER, E. L.; KERR, W. What causes industry agglomeration? Evidence from coagglomeration patterns. American Economic Review, v. 110, n. 3, p. 1.195-1.213, 2007.

FERRAZ, J. C.; KUPFER, D.; HAGUENAUER, L. Made in Brazil: desafios competitivos para a indústria. Rio de janeiro: Campus, p. 386, 1996.

GUIMARÃES NETO, L. Desigualdades e políticas regionais no Brasil: caminhos e descaminhos. Planejamento e Políticas Públicas, n. 15, 1997.

LAUTERT, V.; ARAÚJO, N. C. M. D. Concentração industrial no Brasil no período 19962001: uma análise por meio do índice de Ellison e Glaeser (1994). Economia Aplicada, SciELO Brasil, v. 11, n. 3, p. 347-368, 2007.

LEMOS, M. B.; CUNHA, A. Novas aglomerações industriais e desenvolvimento regional recente no brasil. Revista Econômica do Nordeste, v. 27, n. 4, p. 725-761, 1996.

LEMOS, M. B.; MORO, S.; DOMINGUES, E. P.; RUIZ, R. M. A organização territorial da indústria no Brasil. In: NEGRI, J. A. O. D. et al. Inovações, padrões tecnológicos e desempenho das firmas industriais brasileiras. Brasília: Instituto de Pesquisa Econômica Aplicada, v. 1, p. 325-364, 2005.

NEGRI, F. D.; CAVALCANTE, L. R. Os dilemas e os desafios da produtividade no Brasil. In: NEGRI, F. D.; CAVALCANTE, L. R. (Ed.). Produtividade no Brasil: desempenho e determinantes. Brasília: Ipea-IBDI, 2014. v. 1, cap. 1, p. 15-52.

NEGRI, J. A. O. D.; SALERNO, M. S. O.; ALMEIDA, M.; ALVES, P.; ARAÚJO, R. D. D.; ARBACHE, J. S.; ARBIX, G.; BAESSA, A. R.; BAHIA, L. D.; BRITTO, J. N. D. P.; CASSIOLA$\mathrm{TO}, \mathrm{J}$. E. Inovações, padrões tecnológicos e desempenho das firmas industriais brasileiras. Brasília: Instituto de Pesquisa Econômica Aplicada (IPEA), 2005.

OREIRO, J. L.; FEIJÓ, C. A. Desindustrialização: conceituação, causas, efeitos e o caso brasileiro. Revista de Economia Política, SciELO Brasil, v. 30, n. 2, p. 219-232, 2010.

PACHECO, C. A. Novos padrões de localização industrial? Tendências recentes dos indicadores da produção e do investimento industrial. Brasília: Instituto de Pesquisa Econômica Aplicada (Ipea), 1999. (Texto para Discussão 0633)

RESENDE, M.; WYLLIE, R. Aglomeração industrial no Brasil: um estudo empírico. Estudos Econômicos (São Paulo), v. 35, n. 3, p. 433-460, 2005.

SABOIA, J. Desconcentração industrial no Brasil nos anos 90: um enfoque regional. Pesquisa 
e Planejamento Econômico (PPE), Rio de Janeiro, v. 30, n. 1, p. 69-116, 2000.

SABOIA, J. A continuidade do processo de desconcentração regional da indústria brasileira nos anos 2000. Nova Economia, v. 23, n. 2, p. 219-278, 2013.

SABOIA, J.; KUBRUSLY, L. S.; BARROS, A. C. Caracterização e modificações no padrão regional de aglomeração industrial no Brasil no período 2003-2011. Pesquisa e Planejamento Econômico (PPE), Rio de Janeiro, v. 44, n. 3, p. 635-662, 2014.

SARTI, F.; HIRATUKA, C. Desenvolvimento industrial no Brasil: oportunidades e desafios futuros. Texto para discussão n. 187 Campinas: IE/Unicamp, 2011.

SARTI, F.; HIRATUKA, C. Desempenho recente da indústria brasileira no contexto de mudanças estruturais domésticas e globais. Texto para discussão n. 290. Campinas: IE/ Unicamp, 2017.

SILVA, C. d. F.; SUZIGAN, W. Padrões setoriais de inovação da indústria de transformação brasileira. Estudos Econômicos (São Paulo), SciELO Brasil, v. 44, n. 2, p. 277-321, 2014.

SOBRINHO, E. M. G.; AZZONI, C. R. Aglomerações industriais relevantes do Brasil em 2010. Revista Brasileira de Estudos Regionais e Urbanos, v. 9, n. 1, p. 1-18, 2016.

SOUZA, F. E. P. Por que a indústria parou? In: BARBOSA, N. et al. (Ed.). Indústria e desenvolvimento produtivo no Brasil. Rio de Janeiro: Elsevier-FGV, 2015. v. 1, cap. 1, p. 3-30.

SUZIGAN, W.; FURTADO, J.; GARCIA, R.; SAMPAIO, S. E. Aglomerações industriais no estado de São Paulo. Economia Aplicada, v. 5, n. 4, p. 695-717, 2001.

SUZIGAN, W.; FURTADO, J.; GARCIA, R.; SAMPAIO, S. E. Coeficientes de Gini locacionais-GL: aplicação à indústria de calçados do Estado de São Paulo. Nova Economia, v. 13, n. 2, p. 39-60, 2003.

\section{Sobre os autores}

André Luiz Ferreira e Silva - alufpa@gmail.com

Instituto de Ciências Sociais Aplicadas, Universidade Federal do Pará, Belém, PA, Brasil.

ORCID: https://orcid.org/0000-0002-8140-2444.

Marcelo Bentes Diniz - mbdiniz2007@hotmail.com

Programa de Pós-Graduação em Economia, Universidade Federal do Pará, Belém, PA, Brasil.

ORCID: https://orcid.org/0000-0001-7484-9451.

\section{Sobre 0 artigo}

Recebido em 04 de novembro de 2017. Aprovado em 05 de fevereiro de 2019. 